\title{
The Nature and Determinants of Disclosure Practices in the Insurance Industry: Evidence from European Insurers
}

\author{
Irma Malafronte*, Claudio Porzio, Maria Grazia Starita
}

University of Naples Parthenope, Department of Management Studies and Quantitative Methods, Italy

\begin{abstract}
Filling a gap in the existing literature on disclosure practices by insurance companies, this research provides new empirical evidence on the nature and determinants of disclosure practices in the European insurance industry over the 2005-2010 period. The main results show that insurers are more inclined to invest in the quantity of risk information rather than in the disclosure quality of the entire annual report, as risk information is addressed to high-level financially educated people and requires fewer resources than are needed for an investment in quality. Further, the analysis also shows that insurer level characteristics, in terms of size and technical provisions, as well as country level variables, significantly affect the amount of risk information disclosed. In the years affected by the financial crisis, the level of risk disclosure quantity increases as insurers use disclosure as a tool to reassure stakeholders on their independence from the global financial crisis.
\end{abstract}

Keywords: disclosure, insurance companies, financial crisis

JEL codes: G22, G14, G01

\footnotetext{
${ }^{*}$ Corresponding author. Email address: irma.malafronte@uniparthenope.it (I.Malafronte)
} 


\section{Introduction}

Over the last decades, the attention paid to disclosure issues by the financial literature, by companies, by supervisory authorities and by other companies' stakeholders has increased markedly.

Botosan (1997), Cooke (1989) and a wide subsequent literature have investigated the disclosure practices of non-financial companies, their determinants and their consequences; other research papers have focused on the banking system (i.e., Baumann and Nier 2004; Linsley and Shrives, 2005); still others have started to address this issue by looking at the insurance industry (i.e., Höring and Gründl, 2011; Klumpes et al., 2014). In addition to this increase in scientific attention paid to disclosure, especially in recent years, companies themselves have started to recognise the importance of enhancing disclosure and thus satisfying the needs of investors and financial markets for transparency. Moreover, several regulatory initiatives have sought to enhance the quantity and the quality of disclosure by financial intermediaries and insurance companies; looking at the European insurance industry, the forthcoming Solvency II Directive requires insurance undertakings to disclose financial information publicly through a report both to their supervisors and to the public. Finally, the recent turmoil in world financial markets, in particular since 2008, has outlined the importance of strengthening communication with the entire financial community.

Disclosure can be defined as the action of releasing relevant, new or secret information pertaining to a company, thus making it known and able to influence investment decisions; it is defined as the revealing of knowledge, freeing from secrecy or ignorance, or making known (Lanam, 2007). As observed by Beretta (2007), whereas in the past companies communicated only through mandatory documents (i.e., balance sheets and interim reports) and considered discretion as a value to defend, today firms compete through the dissemination of information. In particular, companies increasingly perceive the annual report as a communication tool towards stakeholders in addition to its main function of reporting financial and economic conditions; it is used to announce important positive results, to manifest core values, and to reassure stakeholders in difficult financial times. For stakeholders, it is necessary to make sound decisions, and primarily regulators, shareholders and customers are interested in its content. Companies are aware of the crucial role assumed by disclosure; it can be beneficial but also costly, and it requires investment and expertise. Thus, the choice is no longer whether to disclose, but to decide strategically when, how and what to communicate.

The existing literature has widely debated issues of disclosure by non-financial companies (i.e., Beretta and Bozzolan, 2004; Botosan, 1997; Ho and Wong, 2001; Linsley and Shrives, 2006; more recently, Eshandidy at. al., 2013). A few papers have paid attention to disclosure practices of banks (i.e., Barakat and Hussainey, 2013; Baumann and Nier, 2004; Perignon and Smith, 2010) and insurance companies (i.e., Höring and Gründl, 2011; and more recently, Klumpes et al., 2014). Moreover, starting from the assumption that disclosure requires not only the dissemination of a set of information but also that this information be understandable by the audience, an emerging stream of literature (i.e., Lanam, 2007; Linsley and Lawrence, 2007) investigates the readability of the documents from the consumer's point of view.

This research is part of the emerging literature on disclosure practices of financial companies. It revisits themes widely developed for non-financial firms, looking at the European insurance industry. More precisely, it aims to investigate the level of disclosure quality, the level of risk disclosure 
quantity and its determinants in a sample of 47 European insurance companies over the 2005-2010 time period. In addition to the lack of research on this topic, studying disclosure issues for insurance companies is particularly interesting due to the unique characteristics of this business (i.e., the provision of insurance cover against risks that imply reversal of the production cycle, the law of large numbers, the relevance of investment activity) with respect to other business sectors (i.e., banking and non-financial sectors) that previous studies have not adequately considered. In fact, risk management assumes a key role in the insurance sector because, unlike other sectors, the core business of insurers is providing protection to policyholders from identified risks through the spreading of the risk itself. Consequently, insurers are risk-taking enterprises and disclosure becomes fundamental for external stakeholders, mainly policyholders and regulators, to control how the risks taken are faced and managed. Thus, looking at disclosure issues among a sample of insurers allows controlling for these specific features that are not analysed in the literature on banks and non-financial companies. Moreover, it is interesting to highlight the role of the insurance industry during the global financial crisis because, unlike other financial institutions, it did not contribute to it through sub-prime mortgages and mortgage-backed financial instruments. Thus, it is interesting to observe whether and how insurers have used disclosure tools to emphasise their lack of connection with the origination and diffusion of the financial crisis.

This paper has three main goals. First, it investigates the level of disclosure quality by analysing the readability and the richness in vocabulary of the annual reports of sampled insurers, and the first research question to answer is: i) Are annual reports of European insurers easy to read and understandable by stakeholders? Second, it focuses on the level of risk disclosure quantity through the construction of a set of new risk disclosure indices because information disclosed on risks plays a key role in the insurer's communication strategy, and it tries to answer a second research question: ii) What is the quantity of risk information disclosed by European insurance companies? After comparing the quality and quantity of disclosure and focusing on the most dynamic aspect of insurer disclosure, the last purpose attempts to identify the determinants of the risk disclosure practices of the sampled insurers, and the third research question is the following: iii) What drives the level of risk disclosure quantity in the annual reports of European insurers?

The main results show that the annual reports are difficult to read; there is no evidence of an effort by companies to enhance the quality of their disclosure practices, as readability levels are quite constant over time; thus a problem of readability arises for consumers and policyholders. It seems that the work on disclosure by insurance companies is addressed towards other stakeholders rather than effective or potential policyholders, for example financial analysts and rating agencies, which normally show higher levels of financial literacy. In fact, in support of this observation, the quantity of risk disclosure has increased over time, with stronger growth between 2008 and 2010, and consequently the lack of a significant relationship between the quality and the quantity is a conscious choice by insurance companies, i.e., they prefer to invest in the least expensive communication strategy goals. Finally, the analysis also shows that risk disclosure practices are driven by the insurer's size and technical provisions; by the home country, its level of insurance development, its GDP and its political stability; and by the financial crisis. 
This paper tries to contribute to the existing literature in two ways. First, it provides new empirical evidence on the nature and determinants of disclosure practices in the insurance industry, taking into account the unique characteristics of this business sector and thus the crucial role of disclosure and risk management for insurers. To this aim, it fills a gap in the emerging literature on disclosure practices in the insurance industry. A complete view of disclosure in the insurance industry is provided by two different criteria for measuring disclosure practices, one for qualitative disclosure (seven pre-defined readability and richness indices) and one for quantitative disclosure (two new risk disclosure indices), considering them first individually and then comparing them. It also introduces new drivers of disclosure practices such as the weight of technical provisions and macroeconomic factors, thus controlling for features of the insurance industry and providing interesting indications to regulators. Second, it tests the potential effects of the financial crisis on disclosure practices, thus it investigates insurance companies' behaviour towards disclosure in periods of crisis, even remarking their disconnection from the origination and diffusion of the financial crisis. To the extent of our knowledge, there are no papers linking the financial crisis and disclosure issues in the European insurance industry.

The remainder of the paper is organised as follows. Section 2 identifies the literature close to this research and develops new hypotheses to test. Section 3 describes the methodology. Section 4 focuses on description of the sample and the variables. Section 5 provides the empirical results and discusses them. Section 6 contains the conclusions, and three appendices conclude the paper.

\section{Literature Review}

Most of the existing literature in the field of disclosure concerns non-financial companies, whereas few recent studies have paid attention to the disclosure practices of banks and insurance companies. This research fits into an emerging stream of the literature that investigates disclosure practices of insurance companies; it focuses on its quality as expressed through readability and richness measures, on its quantity as expressed through risk disclosure level and on its determinants. Thus, the literature summarised below distinguishes between qualitative disclosure, quantitative disclosure and the determinants of risk disclosure levels, also looking at the effects of the financial crisis on risk disclosure quantity.

\subsection{Disclosure practices: the duality between quality and quantity by focusing on the entire annual} report and on a specific part of it

If consumers receive information and are able to read and understand it, they are also able to make optimal decisions in the interest of themselves and of the whole financial system (Cude, 2005). Price ignorance and a lack of effective price competition lead policyholders to pay more than necessary for their insurance protection, thus a rigorous system of price disclosure is necessary to permit buyers to make reasonably informed purchase decisions (Belth, 1968) and understand well what they are doing (Belth, 1976). Starting from these observations, several papers in this field of research analyse the readability of the documents from the consumer's point of view.

The starting point for an effective disclosure is understanding that the intended audience is the consumer; therefore, a good disclosure has to incorporate "simpler and more common, non-legal 
language" and "concrete rather than abstract information". When presenting complex information, "less is more" (Lanam, 2007). In spite of that, the effectiveness of products and price disclosure have not been evaluated for more than twenty years, while product and service designs have become more complicated (Kirsch, 2003) and information disclosed on risk is difficult or very difficult to read (Linsley e Lawrence, 2007).

Linsley and Lawrence (2007) examine risk disclosure by UK companies within their annual reports through the content analysis methodology, finding that the risk disclosures are difficult or very difficult to read; however, no evidence was found to suggest potential obfuscation of the information by directors. Cude (2005) reports the results of three focus groups where the participants were submitted three documents as examples of insurance disclosure. This study documents that there are no differences in understanding disclosure by gender, age, or ethnicity. Moreover, some participants state they generally do not read the disclosure information, but they would read it if the main information appeared immediately and the document was short and readable. In line with this stream of the literature, this research investigates the level of disclosure quality, such as readability and richness in vocabulary, through a set of pre-defined indices for the 2005-2010 annual reports disclosed by European insurers. It is expected that the annual report is quite difficult to read because the description of the insurer's activity requires a complex and special vocabulary (for example, "technical provisions", "embedded options", "run-off”) and that it has become easier to read over time, consistent with the increasing importance that companies give to this document. Indeed, the annual report can be considered as a tool for communicating with stakeholders (i.e., regulators, practitioners, customers) and for maintaining their trust, especially during a period characterised by a financial crisis.

Moreover, the existing literature always measures the quantity of disclosure through a selfconstructed disclosure index (Adams and Hossain, 1998; Barako et al., 2006; Baumann and Nier, 2004; Beretta and Bozzolan, 2004; Beretta and Bozzolan, 2008; Beuselinck et al., 2008; Botosan, 1997; Camffermann and Cooke, 2002; Cooke, 1989; Cooke, 1992; Cooke, 1993; Francis et al., 2007; Hirtle, 2007; Ho and Wong, 2001; Höring and Gründl, 2011; Perignon and Smith, 2010; and more recently, Eshandidy et. al., 2013). A disclosure index is an ex-ante specified list of items; in this process, the documents are analysed to evaluate the presence of these items, and based on the presence and on the amount of information disclosed in them, a score is assigned to each of them (Höring and Gründl, 2011). Botosan (1997) constructs a disclosure index based on five categories of voluntary information that firms provided in their annual reports in 1990; Baumann and Nier (2004) build an index for measuring disclosure in the banking system.

A relatively large number of studies focus on risk disclosure practices, and the results reported are quite controversial. In most of the cases, the quantity of risk disclosure in annual reports is found to increase over time (Lajili and Zeghal, 2005; Perignon and Smith, 2010; van Oorschot, 2010), and accounting and policy are the most disclosed matters (Linsley and Shrives, 2005). However, risk disclosure practices are difficult to compare (Oliveira et al., 2011); banks do not yet provide full risk disclosure, and managers could be reluctant to provide too much information to avoid being judged and giving advantages to competitors (Linsley and Shrives, 2005). Disclosure of operational risk varies across institutions (Sundmacher, 2006); it is greater in extent and is inversely related to equity 
ratio and return on assets (Helbok and Wagner, 2005). Using a sample of European banks, Barakat and Hussainey (2013) show that corporate governance and regulation are the main drivers of operational risk disclosure reporting. In contrast, other studies find that firms provide little or no information about risks (Abraham et al., 2007); risk disclosure, even when in depth, is only marginally useful and clear, thus suggesting the need for a more comprehensive disclosure (Lajili and Zeghal, 2005).

This research investigates the quantity of information disclosed on risk by European insurance companies through the construction of a set of new risk disclosure indices for insurers over a multiyear period because the insurance industry shows some special characteristics that the previous literature does not accurately take into account, such as the complexity of insurance operations, which necessitates a process of unbundling and boiling out of information disclosed on risks taken. According to the lexicon adopted by Chavent et al. (2006)

${ }^{2}$, the insurance sector presents a specific disclosure pattern. It is expected that the level of disclosure quantity increases over time due to the concentration of the insurers' efforts on the description of the main issue of the insurer's activity, which is the management of the risks taken. Furthermore, it is expected that the financial crisis has accelerated the increase of risk disclosure levels to stress the differences between the risks managed by the insurance industry and the behaviour displayed by the banking system and by mutual funds.

\subsection{Determinants of risk disclosure quantity}

An evolution of the last field of literature summarised above goes beyond testing the level of disclosure, trying to identify factors that could explain higher versus lower degrees of risk disclosure. This literature observes that the amount of information disclosed by non-financial firms may be affected by, for example, companies' characteristics (Beretta and Bozzolan, 2004; Cooke, 1992, 1993; Linsley and Shrives, 2006), governance characteristics and ownership structure (Abraham and Cox, 2007; Ho and Wong, 2001) in both developed and emerging markets (Barako et al., 2006). The level of risk disclosure is found to be positively associated with company size and environmental risk (Linsley and Shrives, 2006). Corporate risk reporting is related positively to the number of executives and independent directors but negatively with the amount of shares owned by long-term institutions. Thus, institutional investors prefer firms with a lower level of risk disclosure (Abraham and Cox, 2007). Similar results are found in a developing countries such as Kenya, where Barako et al. (2006) observe that the extent of voluntary disclosure is influenced by corporate governance, ownership structure and the company's characteristics. By contrast, risk disclosure quantity is not significantly influenced by size, industry or performance as shown by Beretta and Bozzolan (2004) and van Oorschot (2010).

Recent papers by Hail (2011), Höring and Gründl (2011), and Klumpes et al. (2014) explore risk disclosure practices in the insurance industry. The first investigates the voluntary disclosure of Embedded Value (EV), finding that even though expensive and not required, more and more

\footnotetext{
${ }^{2}$ Chavent et al. (2006) propose a new methodological approach to analyze non-financial firms' disclosure practices: they identify the disclosure patterns through a divisive (descendant) clustering method. According to this method, disclosure patterns are related to provision intensity, size, leverage and market expectation, but not to profit, return or industry.
} 
companies provide EV disclosures, and this reduces information asymmetry. The second find that the importance of risk disclosure has increased over time, that bigger and more risky insurers show high risk disclosure and disclosure is negatively linked to the insurer's profitability. Furthermore, Klumpes et al. (2014) show that the extent and the nature of risk disclosure practices depend on cultural effects and managerial incentives.

Within this last field of the literature, there seems to remain a lack of a systematic analysis on the determinants of risk disclosure. After measuring the trends of insurers' disclosures in terms of annual report quality and quantity of risk information and controlling for their relationship, the final aim of this paper is to identify the determinants of risk disclosure practices. In particular, this study aims to contribute to the aforementioned debate by investigating the relationship between risk disclosure quantity and a set of factors at the insurer level (size, operating performance, and technical activity) and at the country level (home country, the level of insurance development achieved by each country, and indicators of economic and social conditions, alternatively) while controlling for other variables (the prevalent type of insurance activity, risk, and year dummies).

At the insurer level, it is expected that bigger insurers and insurers with higher performance levels disclose more about risk to maintain their current positioning in the insurance industry in the coming years.

Indeed, several empirical studies (as in Beretta and Bozzolan, 2004; Cooke, 1989; Höring and Gründ, 2011; Linsley and Shrives, 2006) have shown that the amount of disclosure is highly influenced by size; when a company is large, it may suffer additional political costs, the complexity of the business is higher and agency costs increase because monitoring becomes more complex and expensive. This context requires efficient management information systems and highly skilled individuals, resulting in higher investment in disclosure practices to enhance investor, as well as policyholder, confidence (Beretta and Bozzolan, 2004; Cooke, 1989; Höring and Gründl, 2011). Thus, the first hypothesis to test, as it happens for non-financial firms, is the following:

H1. High sales are associated with high risk disclosure quantity.

Different from the literature that finds no significant relationship between profitability and disclosure (i.e., Barako et al., 2006; Camfferman and Cooke, 2002), it is expected that achieving good operating performance could incentivise insurance companies to increase the amount of disclosure on risk, mainly with respect to policyholders, to strengthen their confidence. Thus, the second hypothesis to test, as it happens for non-financial firms, is the following:

H2. High return on assets is associated with high risk disclosure quantity.

Moreover, in the insurance industry, the ability to take risk by an insurance company, that is, the ability to assure, share, and re-assure the risks taken (such as underwriting risk, credit risk, market risk, liquidity risk, and operational risk), can have an impact on the amount of risk information disclosed. As such, it is expected that the amount of technical provisions negatively affects risk disclosure levels as it is the main item in the balance sheet of an insurer, thus a high level of it represents a signal of the strength of an insurance company, i.e., the ability to take risks, for which it is not necessary to disclose more information. Thus, a hypothesis on technical provisions is introduced, which is the third hypothesis to test: 
H3. A high number of technical provisions is associated with low risk disclosure quantity.

At the country level, it is expected that the quantity of information disclosed on risk depends on certain characteristics linked to the home country. This point is particularly interesting when looking at the European landscape, where regulations and culture are different across countries even though the new regulatory framework promotes uniformity across Europe. Indeed, choices about the amount of information provided could depend on the insurer's home country (as in Höring and Gründl, 2011) or the level of insurance development achieved by each country, i.e., the level of insurance density or insurance penetration (CEA, 2011) $)^{3}$, or the economic and social conditions in which the insurer operates $^{4}$ (Feyen et al., 2011). Thus, the fourth hypothesis to test is the following:

H4. The quantity of risk disclosure depends on characteristics of the insurer's country.

\subsection{Effects of the financial crisis on risk disclosure practices}

The recent financial crisis has raised several questions with respect to the role of financial institutions in the real economy. However, the literature on the effects of this "financial tsunami" on disclosure practices is still very limited, and some papers only focus on the role of fair value accounting in the financial crisis. For example, Barth and Landsman (2010) investigate the relationship between the financial crisis and financial reporting on fair values, asset securitisation, derivatives and loan loss provisioning of banks. Most importantly, they find that fair value accounting played little or no role in the financial crisis.

To fill the gap in the existing literature about disclosure issues and the implications of financial turmoil on disclosure practices, this paper provides the first evidence of a link between the financial crisis and risk disclosure practices of insurance companies. It aims to test whether in a period of crisis insurance companies invested more in disclosure as a tool to reassure stakeholders, or instead, whether the crisis had no specific impact on their disclosure policies. It is expected that the quantity of risk information disclosed depends on the desire to emphasise the lack of connection between the insurance sector and the origination and diffusion of the financial crisis. Thus, the fifth hypothesis to test is the following:

H5. The quantity of risk disclosure increases during a financial crisis.

\section{Methodology}

\subsection{Qualitative disclosure versus quantitative disclosure}

Levels of disclosure are measured through content analysis methodology, a research technique for the objective, systematic and quantitative description of the manifest content of communication (Berelson, 1952). It is also defined as a research technique for making replicable and valid inferences from texts or other meaningful matter - art, images, maps, sounds, signs, symbols - to the contexts of

\footnotetext{
${ }^{3}$ These variables are often used as measures of the development of an insurance market. The greater the insurance density or penetration the greater the level of insurance development (CEA, 2011).

${ }^{4} \mathrm{We}$ are very grateful to an anonymous referee for this suggestion.
} 
their use (Krippendorff, 2004). It involves specialised procedures and increases researchers' understanding of particular phenomena that otherwise could not be studied.

Moreover, it represents the main technique adopted by the existing literature in this field (i.e., Baumann and Nier, 2004; Höring and Gründl, 2011; Linsley and Shrives, 2006; Sundmacher, 2006).

This methodology is introduced in this research in two different ways and the aim is twofold: measuring both the quality and the quantity of disclosure provided by insurance companies in their annual reports, and then comparing these two measures. To this end, two different approaches are proposed:

1. Qualitative disclosure. First, it measures the readability and richness of vocabulary of the annual reports of sample companies through a set of specific indices and through the use of software appropriate for text analysis.

2. Quantitative disclosure. Second, it measures the level of risk disclosure in the annual reports of sample companies through the construction of a set of new risk disclosure indices especially built for insurers, which requires careful reading of the risk information disclosed in each insurer's report.

\subsubsection{Qualitative disclosure.}

To measure the quality of disclosure in the annual reports of European insurers, a set of qualitative disclosure indices is calculated for each annual report collected, considering its whole content. Table 1 reports a list of these indices, and for each of them it provides a brief description. Further details about the formulas and the interpretation of the readability indices are reported in the Appendix A.

Through mathematical formulas that take into account the number of characters, words, sentences, syllables, types and tokens composing the document, these indices express the ease of reading of the text and thus constitute a measure of the readability of each document and the richness of its vocabulary ${ }^{5}$. This type of analysis is necessarily supported by the use of a program that elicits statistics from a text. In this research, the programs QDA Miner ${ }^{6}$ and Wordstat ${ }^{7}$ are used.

\subsubsection{Quantitative disclosure.}

The quantity of disclosure is measured through the construction of a set of new risk disclosure indices. This process consists of analysing the content of the documents to evaluate the presence of an ex-ante specified list of items, and based on the presence and the amount of each item, a score is assigned to each of them.

More precisely, whereas the analysis of the quality of disclosure (readability and richness) refers to the whole content of the annual reports collected, when the investigation is on the quantity of disclosure, the field of inquiry is narrowed to a specific section of the annual reports, which is the risk management section, because it is significant with respect to the insurance business.

\footnotetext{
${ }^{5}$ In order to ensure the validity of the results, each document should be at least 300 words long.

6 "QDA Miner" is a qualitative data analysis software package for coding, annotating, retrieving and analyzing small and large collections of documents and images; it analyzes interview and focus group transcripts, legal documents, journal articles, speeches, even entire books, as well as drawings, photographs, paintings, and other types of visual documents.

7 "Wordstat" is a text analysis program integrated into QDA Miner for analyzing text and relating its content to structured information, including numerical and categorical data.
} 


\section{Table 1}

Qualitative Disclosure

\begin{tabular}{|c|c|c|c|}
\hline \multicolumn{2}{|c|}{ Qualitative Disclosure Indices } & Label & Description \\
\hline \multicolumn{4}{|c|}{ Readability Indices } \\
\hline (Eq. (1)) & Gunning's Fog Index & READl & Grade level necessary to understand a text \\
\hline (Eq. (2)) & Flesch Index & $R E A D 2$ & Ease of reading of a text \\
\hline (Eq. (3)) & Kincaid Index & READ3 & Grade level necessary to understand a text \\
\hline (Eq. (4)) & Coleman-Liau Index & READ4 & Grade level necessary to understand a text \\
\hline (Eq. (5)) & Automated Readability Index & READ5 & Grade level necessary to understand a text \\
\hline \multicolumn{4}{|c|}{ Richness Indices } \\
\hline (Eq. (6)) & Type/Token Ratio (TTR) & RICHI & Variety of the text vocabulary \\
\hline (Eq. (7)) & Hapax Index & $\mathrm{RICH} 2$ & Number of words with frequency $=1$ \\
\hline
\end{tabular}

Notes: This table reports a list of the indices chosen to measure the quality of disclosure in the annual reports of the sample companies. For each index, it provides a brief description. The first five indices (numbers from 1 to 5) measure the readability of the documents and, as a result, indicate the ease of reading or the grade level required to read and understand the text. The last two indices (numbers 6 and 7) measure the richness of the vocabulary, based on its variety and words' frequency. See Appendix $A$ for details about the formulas and the interpretation of these indices.

Thus, the focus is on risk disclosure practices (as in Abraham and Cox, 2007; Abraham et al., 2007; Barakat and Hussainey, 2013; Barako et al., 2006; Beretta and Bozzolan, 2004; Deumes, 2008; Hail, 2011; Helbok and Wagner, 2005; Höring and Gründl, 2011; Lajili and Zeghal, 2005; Linsley and Shrives, 2005; Linsley and Shrives, 2006; Oliveira et al., 2011; Perignon and Smith, 2010; Sundmacher, 2006; van Oorschot, 2010), and the analysis of disclosure quantity refers to the risk management section because it is a crucial activity and a source of value creation for financial intermediaries, which can be defined as risk-taking enterprises and thus are expected to disclose riskrelated information. Moreover, the global financial crisis, which took hold in the third quarter of 2008, has left important challenges for insurance companies to face, resulting in stronger attention to risk management activities to highlight their disconnection from the financial crisis. Therefore, a content analysis approach is implemented to measure the amount of risk information provided by the sample firms in their annual reports over the 2005-2010 time period, and a Risk Disclosure Index for Insurers $(R D I I)$ is obtained. The mathematical formula is:

$R D I I_{i, t}=\sum_{j=1}^{30}$ Score $_{j}$

where $i$ represents the company, $t$ is the year the annual report refers to, $j$ indicates each item included in the index. Thus, the value of the index for each company $i$ for the year $t$ is obtained as the sum of the scores (Score) assigned to each item $j$.

It can be standardised as follows:

$$
R_{D I I} I_{i, t}=\left(\sum_{j=1}^{30} \text { Score }_{j} / \text { Maxscore }\right) \times 100=\left(\text { Total score }_{i, t} / \text { Maximum possibe score }\right) \times 100
$$

The items included in the RDII are selected by looking at the literature (Baumann and Nier, 2004; Botosan, 1997; Höring and Gründl, 2011), taking into account the peculiarities of the insurance companies and checking for IFRS requirements to focus on information different from that required. The 30 items are organised into seven areas:

- risk management (4 items),

- underwriting risk (4 items),

- market risk (4 items), 
- credit risk (4 items),

- operational risk (4 items),

- liquidity risk (4 items),

- other risks (6 items).

As a general rule, each item is assigned a score between " 0 " and " 2 ": " 0 " when there is no disclosure, "1" when the information is provided in a basic way, " 2 " when the information is provided in an extensive way (Table 2). In addition, a total score is calculated, assigning each item another score between "0" and " 4 "; this allows clearer expression of the judgment, but it implies more subjectivity by the researcher. The maximum possible score is equal to 38 (if the range is $0-2$ ) or 54 (if the range is 0-4). The value of the standardised $R D I I$ ranges between 0 and 100, with 0 reflecting the worst risk disclosure practices and 100 representing the best risk disclosure practices.

See Appendix B for details about the items and the potential scores assigned to each of them.

\section{Table 2}

Quantitative Disclosure

\begin{tabular}{clcc}
\hline \multicolumn{1}{l}{ Risk Disclosure Index for Insurers (RDII) } & Rescription & Lowest & Highest \\
\hline \multicolumn{2}{c}{ Label } & \multicolumn{1}{c}{ Is composed of 30 items; } \\
\hline RDII_02 & - Each item is assigned a score between 0 and 2. & $0-38$ & 38 \\
\hline RDII_04 & $\begin{array}{l}\text { - Is composed of 30 items; } \\
\text { - Each item is assigned a score between 0 and 4. }\end{array}$ & $0-54$ & 0 \\
\hline
\end{tabular}

Notes: This table contains some information about the Risk Disclosure Index for Insurers (RDII), constructed in order to measure the level of risk disclosure in the management reports of the sample companies. See Appendix $B$ for details about the items and the scores assignable to each of them.

\subsection{Determinants of risk disclosure practices}

To test the hypotheses presented in Section 2, a basic model (10) estimates the relationship between risk disclosure level ${ }^{8}$ and certain variables at the insurer, country, and control level, as follows:

$\operatorname{RDII}_{i, t}=\alpha+\beta_{1} \operatorname{SALES}_{i, t}+\beta_{2}$ ROA $_{i, t}+\beta_{3}$ RESERVE $_{i, t}+\beta_{4}$ HOME $_{i, t}+\sum_{j=1}^{n} \beta_{1} \operatorname{CONTROL}_{i, t}$

where $i(i=1, \ldots, 47)$ represents the insurance company, $t(t=2005, \ldots, 2010)$ identifies each year over the time period investigated, $j(j=1, \ldots, n)$ is the number of control variables.

A set of panel data regressions is estimated, coherently with the panel structure of the sample; in particular, they are random effects regressions that control for the cross-sectional differences as well as the country differences between insurers in the sample.

This regression model allows investigation of the impact of a set of characteristics at the insurer level: the logarithm of sales (SALES), the return on assets $(R O A)$, the weight of technical provisions on the sum of total liabilities and shareholder equity (RESERVE); and a set of characteristics at the country level, measured by dummy variables that refer to the country where the company has its legal

\footnotetext{
${ }^{8}$ The analysis of the determinants of the readability and richness of disclosure is not provided as it has been considered relevant to focus the analysis on risk disclosure due to the importance of risk management activity for a financial intermediary.
} 
base (HOME1), the level of insurance development of the country to which it belongs (HOME2density), and two country-specific variables (the growth of gross domestic product by country (GDP) and a measure of political stability (STABILITY)) on risk disclosure levels by the sample companies ${ }^{9}$. It also controls (CONTROL) for the prevalent type of insurance activity (TYPE), the ratio between the accounting value and the market value of equity $(R I S K)$, and the year the annual report refers to (YEAR).

In a second model specification, the year dummies are replaced by a financial crisis (CRISIS) variable to test the impact of the financial turmoil on risk disclosure.

\section{Sample and data}

This research makes use of a unique dataset containing information on a sample of European insurance companies. This dataset provides information on the disclosure practices and characteristics of 47 insurance companies operating across Europe, which represent just over $50 \%$ of the European insurance industry $(\mathrm{CEA}, 2011)^{10}$ in terms of premiums collected, and it refers to the 2005-2010 time period.

The sample selection process is summarised in Table 3. It starts by considering all the companies included in the "STOXX ${ }^{\circledR}$ All Europe TMI"11, which at the time the sample was selected numbered 1,517. Then, consistent with the purpose of this research, non-financial companies and financial companies not operating in the insurance industry are dropped from the sample, leading to an initial sample of 52 companies. Five of these firms are further dropped because the annual reports are not available. This process yields a final sample of 47 insurance companies and 279 annual reports available over a six-year period.

Data are taken from companies' annual reports and balance sheets from the 2005-2010 time period available on their websites in the Investor Relations section.

\footnotetext{
${ }^{9}$ The authors thank an anonymous referee for the suggestions provided to improve the methodology section, in particular about the panel methodology and the robustness checks.

${ }^{10}$ More precisely, the total amount of premiums collected by the sample companies corresponds to more than $50 \%$ of the premiums collected by the insurance companies included in the Insurance Europe dataset, whose statistics are reported in the CEA (2011) report.

${ }^{11}$ The "STOXX ${ }^{\circledR}$ All Europe TMI" represents the Western and Eastern Europe region as a whole, covering approximately 95 percent of the free floating market capitalization of European companies with a variable number of components (see www.stoxx.com website). This index includes companies operating in nineteen different sectors: Automobiles \& Parts (34 companies), Banks (134), Basic Resources (86), Chemicals (48), Construction \& Materials (90), Financial Services (78), Food \& Beverages (75), Healthcare (81), Industrial Goods \& Services (244), Insurance (52), Media (52), Oil \& Gas (88), Personal \& Household Goods (73), Real Estate (70), Retail (69), Technology (65), Telecommunications (43), Travel \& Leisure (56), and Utilities (79).
} 
Table 3

Sample selection process

\begin{tabular}{|c|c|}
\hline Sample selection process & Number \\
\hline Companies included in the $S T O X X^{\circledR}$ All Europe TMI & 1,517 \\
\hline \multicolumn{2}{|l|}{ Less: } \\
\hline Non-financial companies & $(1,253)$ \\
\hline Financial companies not operating in the insurance industry & $(212)$ \\
\hline Insurance companies included in the STOXX ${ }^{\circledR}$ All Europe TMI & 52 \\
\hline Companies dropped out because of no availability of annual reports & $(5)$ \\
\hline Final sample & 47 \\
\hline
\end{tabular}

The annual report is just one of the multiple channels through which companies communicate with their stakeholders ${ }^{12}$; in support of this choice, the literature shows that it is the main disclosure vehicle (Marston and Shrives, 1991), it is an influential source of information because of its wide coverage and availability (Beretta and Bozzolan, 2004) and annual report disclosure levels are positively correlated with the amount of corporate disclosure provided via other media (Lang and Lundholm, 1993).

Table 4 describes the variables employed to investigate the phenomenon and provides some descriptive statistics. For each firm, this paper follows two criteria to measure disclosure practices, one measuring the disclosure quality and one measuring the risk disclosure quantity. Furthermore, for each company it constructs several firm-specific variables.

\section{Table 4}

Summary of variables

\begin{tabular}{|c|c|c|c|c|c|c|c|}
\hline \multirow{2}{*}{ Variable } & \multirow{2}{*}{ Description } & \multicolumn{6}{|c|}{ Descriptive statistics } \\
\hline & & Mean & St.Dev. & Min. & Median & Max. & Obs. \\
\hline \multicolumn{8}{|c|}{ Qualitative disclosure } \\
\hline$R E A D 1_{i t}$ & $\begin{array}{l}\text { is the first measure (1) of the readability of the } \\
\text { annual report for the year } t \text { by the insurer } i \text { (as } \\
\text { described in Appendix A) }\end{array}$ & 18.33 & 2.45 & 11.26 & 18.20 & 27.51 & 251 \\
\hline$R E A D 2_{i t}$ & $\begin{array}{l}\text { is the second measure (2) of the readability of the } \\
\text { annual report for the year } t \text { by the insurer } i \text { (as } \\
\text { described in Appendix A) }\end{array}$ & 31.08 & 11.19 & 0.28 & 31.21 & 61.88 & 251 \\
\hline$R E A D 3_{i t}$ & $\begin{array}{l}\text { is the third measure (3) of the readability of the } \\
\text { annual report for the year } t \text { by the insurer } i \text { (as } \\
\text { described in Appendix A) }\end{array}$ & 15.51 & 2.03 & 9.16 & 15.61 & 23.96 & 251 \\
\hline$R E A D 4_{i t}$ & $\begin{array}{l}\text { is the fourth measure (4) of the readability of the } \\
\text { annual report for the year } t \text { by the insurer } i \text { (as } \\
\text { described in Appendix A) }\end{array}$ & 14.33 & 2.22 & 8.35 & 14.24 & 20.72 & 251 \\
\hline
\end{tabular}

\footnotetext{
${ }^{12}$ Companies provide information through their annual reports, which are published periodically; they can also send communication to the analysts or the market when particular events occur. Information about the companies may come from external parties, too (i.e., financial analysts, rating agencies, supervisory authorities).
} 


\begin{tabular}{|c|c|c|c|c|c|c|c|}
\hline$R E A D 5_{i t}$ & $\begin{array}{l}\text { is the fifth measure (5) of the readability of the } \\
\text { annual report for the year } t \text { by the insurer } i \text { (as } \\
\text { described in Appendix A) }\end{array}$ & 15.91 & 2.47 & 5.57 & 15.96 & 27.03 & 251 \\
\hline $\mathrm{RICH}_{i t}$ & $\begin{array}{l}\text { is the first measure (6) of the richness in } \\
\text { vocabulary of the annual report for the year } t \text { by } \\
\text { the insurer } i \text { (as described in Appendix A) }\end{array}$ & 0.07 & 0.04 & 0.03 & 0.07 & 0.50 & 251 \\
\hline $\mathrm{RICH}_{i t}$ & $\begin{array}{l}\text { is the second measure ( } 7 \text { ) of the richness in } \\
\text { vocabulary of the annual report for the year } t \text { by } \\
\text { the insurer } i \text { (as described in Appendix A) }\end{array}$ & 0.03 & 0.03 & 0.01 & 0.02 & 0.34 & 251 \\
\hline \multicolumn{8}{|c|}{ Quantitative disclosure } \\
\hline RDII_O2 ${ }_{i t}$ & $\begin{array}{l}\text { is the risk disclosure index for insurers assigned } \\
\text { to the insurer } i \text { and referred to the annual report } \\
\text { for the year } t \text { (range 0-2) (as described in } \\
\text { Appendix B) }\end{array}$ & 21.93 & 6.42 & 2 & 23 & 35 & 279 \\
\hline RDII_04 ${ }_{i t}$ & $\begin{array}{l}\text { is the risk disclosure index for insurers assigned } \\
\text { to the insurer } i \text { and referred to the annual report } \\
\text { for the year } t \text { (range 0-4) (as described in } \\
\text { Appendix B) }\end{array}$ & 26.52 & 8.37 & 2 & 28 & 45 & 279 \\
\hline \multicolumn{8}{|c|}{ Insurer level characteristics } \\
\hline$S A L E S_{i t}$ & $\begin{array}{l}\text { is the logarithm of the amount of sales, as in the } \\
\text { balance sheet of the firm } i \text { for the year } t\end{array}$ & 8.94 & 1.58 & 5.36 & 8.89 & 11.72 & 231 \\
\hline$R O A_{i t}$ & $\begin{array}{l}\text { is the ratio between operating income and total } \\
\text { assets of the firm } i \text { for the year } t\end{array}$ & 0.03 & 0.04 & $<0.00$ & 0.01 & 0.21 & 231 \\
\hline$R E S E R V E_{i t}$ & $\begin{array}{l}\text { is the ratio between technical provisions and the } \\
\text { sum of total liabilities and shareholders' equity of } \\
\text { the firm } i \text { for the year } t\end{array}$ & 0.78 & 0.16 & 0.15 & 0.84 & 0.97 & 231 \\
\hline \multicolumn{8}{|c|}{ Country level characteristics } \\
\hline HOME1 & $\begin{array}{l}13 \text { dummies capturing the home country of each } \\
\text { insurer (as shown in Appendix C) }\end{array}$ & - & - & - & - & - & 231 \\
\hline $\begin{array}{l}\text { HOME2- } \\
\text { density }\end{array}$ & $\begin{array}{l}\text { a dummy that takes the value of } 1 \text { if the insurance } \\
\text { density of the home country is higher/equal } \\
\text { than/to the sample median (that is } 3,271 \text { euros }{ }^{13} \\
\text { (as shown in Appendix C) }\end{array}$ & - & - & - & - & - & 231 \\
\hline$G D P_{t}$ & $\begin{array}{l}\text { is the annual growth rate of gross domestic } \\
\text { product provided by OECD statistics, by country, } \\
\text { for the year } t\end{array}$ & 1.19 & 3.10 & -8.54 & 1.80 & 9.16 & 231 \\
\hline$S T A B I L I T Y_{t}$ & $\begin{array}{l}\text { is a measure of political stability provided in the } \\
\text { World Bank dataset, by country, for the year } t\end{array}$ & 0.61 & 0.53 & -1.03 & 0.56 & 1.59 & 231 \\
\hline \multicolumn{8}{|c|}{ Other variables } \\
\hline$T Y P E_{i}$ & $\begin{array}{l}2 \text { dummies capturing the prevalent type of } \\
\text { insurance activity }\end{array}$ & - & - & - & - & - & 231 \\
\hline$R I S K_{i t}$ & $\begin{array}{l}\text { is the ratio between the accounting value and the } \\
\text { market value of equity of the firm } i \text { for the year } t\end{array}$ & 0.94 & 0.58 & 0.08 & 0.85 & 4.12 & 231 \\
\hline YEAR & 6 dummies capturing the year data & - & - & - & - & - & 231 \\
\hline \multicolumn{8}{|c|}{ Financial crisis } \\
\hline CRISIS & $\begin{array}{l}\text { is a dummy variable equal to } 1 \text { for the years } 2008 \text {, } \\
2009 \text { and } 2010,0 \text { otherwise }\end{array}$ & - & - & - & - & - & 231 \\
\hline
\end{tabular}

Notes: This table contains a description of the variables included in the analysis and reports some descriptive statistics: mean, standard deviation, minimum, median and maximum.

\footnotetext{
${ }^{13}$ The insurance density is the volume of gross premiums (written at the country level) per capita for the year 2010 (CEA, 2011). In unreported table, we also use the insurance penetration variable, that is measured as the gross value of insurance premiums (written at the country level) in 2010 as a percentage of GDP for the year 2010; consequently, the HOME2penetration variable is a dummy variable that takes the value of 1 if the insurance penetration is higher/equal than/to the sample median (that is equal to 0.1 ).
} 


\section{Results}

\subsection{Levels of disclosure quality and of risk disclosure quantity}

The first purpose of this paper concerns investigating the quality of disclosure through a set of predefined indices and the quantity of risk disclosure by way of a set of new self-constructed indices on the sampled insurers and comparing them.

First, Table 5 displays the readability and richness index values as measures of disclosure quality. Second, Table 6 shows descriptive statistics of the risk disclosure indices to focus on the most important item in the disclosure quantity issues by insurance companies, which is risk information; these last statistics are provided both for the index based on the range 0-2 (RDII_O2) and for the index based on the range 0-4 (RDII_04).

Both the tables refer to the period 2005-2010 and also report the aggregate statistics for the "precrisis" (2005-2007) and "during the crisis" (2008-2010) periods to investigate the trend of the two dimensions of disclosure phenomenon.

5.1.1 The level of disclosure quality: are annual reports of European insurers easy to read and understandable by stakeholders?

The results of Table 5 show that, to read and understand the text of an insurer's annual report in the sample, a grade level is required, on average and for the whole time horizon, equal to 18.33 for $R E A D 1,15.51$ for $R E A D 3,14.33$ for $R E A D 4$, and 15.91 for $R E A D 5^{14}$. If it is considered that documents, in general, are considered understandable for readability levels in the $14^{\text {th }}-15^{\text {th }}-18^{\text {th }}$ grades ${ }^{15}$, it is possible to state that the annual reports published by European insurers on their websites between 2005 and 2010 appear difficult to read. The values reported in each single year over the 2005-2010 time period are very near to the average values, and the standard deviations are narrow. Thus, the annual reports' readability is low, but contrary to expectations, it is quite the same over the six-year time horizon; it seems that there was no commitment by companies to make their documents easier to read over time or to increase the disclosure quality of their annual reports.

This first perception is also confirmed looking at READ2, which is different from the other readability indices from a methodological point of view (see Appendix A). Indeed, READ2 reports an average value of 31.08 for the whole time horizon and corresponds to a difficult readability level. It is the very fact that the average values of the readability indices are quite the same over the entire time horizon that makes the analysis of richness in the vocabulary of the annual reports empirically interesting to test the behaviour of insurers in the sample. RICHI shows that $7 \%$ of the tokens are different and $\mathrm{RICH} 2$ reports that $3 \%$ of the words occur once for the whole time horizon. Contrary to expectations and in line with the evidence from the readability indices, these results fail to detect an attempt by companies to simplify the vocabulary used, underlining and confirming the observations above about the readability of the text.

\footnotetext{
${ }^{14}$ See below for the comments on READ2.

${ }^{15}$ It means that documents are expected to be readable by an average student in their fourteenth year of school, otherwise a student of age around 19 .
} 
Table 5

Descriptive statistics of the readability indices.

\begin{tabular}{|c|c|c|c|c|c|c|c|c|c|}
\hline \multirow{2}{*}{ Variable } & \multirow{2}{*}{ Year } & \multirow{2}{*}{ Obs. } & \multirow{2}{*}{ Mean } & \multirow{2}{*}{ Stand.dev. } & \multirow{2}{*}{ Minimum } & \multicolumn{3}{|c|}{ Percentile } & \multirow{2}{*}{ Maximum } \\
\hline & & & & & & $25 \%$ & $50 \%$ & $75 \%$ & \\
\hline \multicolumn{10}{|l|}{ READI } \\
\hline & 2005 & 38 & 18.52 & 2.29 & 14.74 & 16.54 & 18.86 & 20.30 & 22.98 \\
\hline & 2006 & 44 & 18.12 & 2.17 & 12.27 & 16.81 & 18.11 & 19.35 & 23.79 \\
\hline & 2007 & 41 & 18.39 & 2.06 & 14.75 & 16.75 & 18.28 & 19.95 & 23.39 \\
\hline & crisis (2005-2007) & 123 & 18.33 & 2.16 & 12.27 & 16.59 & 18.28 & 19.80 & 23.79 \\
\hline & 2008 & 42 & 17.75 & 2.64 & 12.62 & 15.59 & 17.49 & 19.55 & 24.22 \\
\hline & 2009 & 42 & 18.37 & 2.99 & 11.26 & 16.69 & 18.37 & 19.80 & 27.51 \\
\hline & 2010 & 44 & 18.84 & 2.43 & 14.59 & 17.29 & 18.32 & 20.46 & 25.40 \\
\hline during th & crisis (2008-2010) & 128 & 18.33 & 2.71 & 11.26 & 16.61 & 18.08 & 19.82 & 27.51 \\
\hline whole & eriod $(2005-2010)$ & 251 & 18.33 & 2.45 & 11.26 & 16.59 & 18.20 & 19.80 & 27.51 \\
\hline \multicolumn{10}{|l|}{ READ2 } \\
\hline & 2005 & 38 & 31.74 & 12.22 & 7.24 & 22.6 & 30.77 & 40.37 & 60.9 \\
\hline & 2006 & 44 & 30.14 & 10.94 & 11.42 & 23.79 & 28.29 & 38.02 & 61.88 \\
\hline & 2007 & 41 & 31.19 & 8.83 & 14.62 & 24.15 & 31.58 & 36.59 & 48.34 \\
\hline & crisis (2005-2007) & 123 & 30.98 & 10.65 & 7.24 & 23.45 & 30.71 & 38.57 & 61.88 \\
\hline & 2008 & 42 & 32.28 & 11.12 & 7.99 & 24.65 & 31.65 & 40.29 & 52.42 \\
\hline & 2009 & 42 & 32 & 13.06 & 0.28 & 24.31 & 33.34 & 40.35 & 60.13 \\
\hline & 2010 & 44 & 29.31 & 10.98 & 2.13 & 20.89 & 30.14 & 37.37 & 52.15 \\
\hline during th & crisis (2008-2010) & 128 & 31.16 & 11.73 & 0.28 & 22.78 & 31.77 & 39.62 & 60.13 \\
\hline whole & eriod (2005-2010) & 251 & 31.08 & 11.19 & 0.28 & 23.44 & 31.21 & 39.28 & 61.88 \\
\hline \multicolumn{10}{|l|}{ READ3 } \\
\hline & 2005 & 38 & 15.44 & 2.21 & 11.7 & 13.57 & 15.59 & 17.25 & 19.75 \\
\hline & 2006 & 44 & 15.59 & 1.89 & 10.34 & 14.31 & 15.77 & 16.64 & 19.69 \\
\hline & 2007 & 41 & 15.44 & 1.57 & 12.19 & 14.26 & 15.51 & 16.51 & 18.23 \\
\hline & crisis (2005-2007) & 123 & 15.49 & 1.89 & 10.34 & 14.07 & 15.66 & 16.76 & 19.75 \\
\hline & 2008 & 42 & 15.3 & 1.96 & 10.71 & 13.95 & 15.37 & 16.93 & 19.21 \\
\hline & 2009 & 42 & 15.45 & 2.65 & 9.16 & 14.11 & 15.19 & 16.61 & 23.96 \\
\hline & 2010 & 44 & 15.8 & 1.82 & 12.62 & 14.24 & 15.82 & 17.17 & 20.02 \\
\hline during th & crisis (2008-2010) & 128 & 15.52 & 2.16 & 9.16 & 14.13 & 15.46 & 16.93 & 23.96 \\
\hline whole & eriod (2005-2010) & 251 & 15.51 & 2.03 & 9.16 & 14.11 & 15.61 & 16.93 & 23.96 \\
\hline \multicolumn{10}{|l|}{ READ4 } \\
\hline & 2005 & 38 & 14.52 & 2.17 & 8.94 & 13.06 & 14.83 & 16.01 & 18.95 \\
\hline & 2006 & 44 & 14.57 & 2.08 & 8.35 & 13.36 & 14.83 & 16.01 & 18.36 \\
\hline & 2007 & 41 & 14.31 & 14.31 & 9.53 & 13.06 & 14.24 & 16.01 & 17.77 \\
\hline & crisis (2005-2007) & 123 & 14.47 & 2.04 & 8.35 & 13.06 & 14.83 & 16.01 & 18.95 \\
\hline & 2008 & 42 & 14.13 & 2.43 & 8.35 & 13.06 & 14.24 & 15.42 & 19.54 \\
\hline & 2009 & 42 & 14.18 & 2.25 & 8.94 & 13.06 & 14.24 & 15.42 & 20.72 \\
\hline & 2010 & 44 & 14.25 & 2.51 & 8.35 & 12.47 & 14.24 & 16.3 & 18.95 \\
\hline during th & crisis (2008-2010) & 128 & 14.19 & 2.38 & 8.35 & 12.47 & 14.24 & 15.71 & 20.72 \\
\hline whole & eriod (2005-2010) & 251 & 14.33 & 2.22 & 8.35 & 13.06 & 14.24 & 16.01 & 20.72 \\
\hline \multicolumn{10}{|l|}{ READ5 } \\
\hline & 2005 & 38 & 16.11 & 2.51 & 11.17 & 13.95 & 16.15 & 17.83 & 21.63 \\
\hline & 2006 & 44 & 16.01 & 2.12 & 10.18 & 15.09 & 16.27 & 17.15 & 20.63 \\
\hline & 2007 & 41 & 15.79 & 2.05 & 9.97 & 14.54 & 15.98 & 17.15 & 20.47 \\
\hline & crisis (2005-2007) & 123 & 15.97 & 2.21 & 9.97 & 14.65 & 16.09 & 17.38 & 21.63 \\
\hline & 2008 & 42 & 15.68 & 2.56 & 10.48 & 13.89 & 15.72 & 17.74 & 21.67 \\
\hline & 2009 & 42 & 15.94 & 3.25 & 5.57 & 14.29 & 15.76 & 17.18 & 27.03 \\
\hline & 2010 & 44 & 15.93 & 2.29 & 11.23 & 14.08 & 15.77 & 17.45 & 20.56 \\
\hline during th & crisis (2008-2010) & 128 & 15.85 & 2.70 & 5.57 & 14.08 & 15.76 & 17.48 & 27.03 \\
\hline whole & eriod $(2005-2010)$ & 251 & 15.91 & 2.47 & 5.57 & 14.29 & 15.96 & 17.46 & 27.03 \\
\hline \multicolumn{10}{|l|}{ RICH1 } \\
\hline & 2005 & 38 & 0.09 & 0.03 & 0.03 & 0.06 & 0.08 & 0.1 & 0.21 \\
\hline & 2006 & 44 & 0.07 & 0.02 & 0.03 & 0.05 & 0.07 & 0.09 & 0.13 \\
\hline
\end{tabular}




\begin{tabular}{|c|c|c|c|c|c|c|c|c|}
\hline 2007 & 41 & 0.07 & 0.03 & 0.03 & 0.05 & 0.07 & 0.09 & 0.14 \\
\hline pre-crisis $(2005-2007)$ & 123 & 0.08 & 0.03 & 0.03 & 0.05 & 0.07 & 0.09 & 0.21 \\
\hline 2008 & 42 & 0.07 & 0.02 & 0.03 & 0.05 & 0.06 & 0.08 & 0.13 \\
\hline 2009 & 42 & 0.08 & 0.08 & 0.03 & 0.05 & 0.06 & 0.08 & 0.50 \\
\hline 2010 & 44 & 0.06 & 0.03 & 0.03 & 0.05 & 0.06 & 0.08 & 0.24 \\
\hline during the crisis $(2008-2010)$ & 128 & 0.07 & 0.05 & 0.03 & 0.05 & 0.06 & 0.08 & 0.50 \\
\hline whole period (2005-2010) & 251 & 0.07 & 0.04 & 0.03 & 0.05 & 0.07 & 0.09 & 0.50 \\
\hline \multicolumn{9}{|l|}{$\mathrm{RICH} 2$} \\
\hline 2005 & 38 & 0.03 & 0.02 & 0.01 & 0.02 & 0.03 & 0.04 & 0.11 \\
\hline 2006 & 44 & 0.03 & 0.01 & 0.01 & 0.02 & 0.03 & 0.03 & 0.06 \\
\hline 2007 & 41 & 0.03 & 0.01 & 0.01 & 0.02 & 0.02 & 0.03 & 0.06 \\
\hline pre-crisis $(2005-2007)$ & 123 & 0.03 & 0.01 & 0.01 & 0.02 & 0.03 & 0.04 & 0.11 \\
\hline 2008 & 42 & 0.02 & 0.01 & 0.01 & 0.02 & 0.02 & 0.03 & 0.06 \\
\hline 2009 & 42 & 0.04 & 0.06 & 0.01 & 0.02 & 0.02 & 0.03 & 0.34 \\
\hline 2010 & 44 & 0.02 & 0.02 & 0.01 & 0.02 & 0.02 & 0.03 & 0.12 \\
\hline during the crisis $(2008-2010)$ & 128 & 0.03 & 0.03 & 0.01 & 0.02 & 0.02 & 0.03 & 0.34 \\
\hline whole period $(2005-2010)$ & 251 & 0.03 & 0.03 & 0.01 & 0.02 & 0.02 & 0.03 & 0.34 \\
\hline
\end{tabular}

Notes: This table contains some descriptive statistics of readability and richness indices as measures of the overall quality of disclosure. The statistics are provided for each year from 2005 to 2010 and, then, distinctly for the pre-crisis (20052007) and during the crisis (2008-2010) periods and the whole period, for all the sample companies.

It means that the annual reports are difficult or very difficult to read in both the pre-crisis period and the crisis period as the number of school years required to read and understand the reports of the sample insurers is very high. As such, the reader should be at least a university student to understand them; thus, there could be a lack of reading, maybe due to a writing problem. More precisely, it could be stated that the annual reports are difficult to read by consumers with no financial expertise, but their content may still be understandable by more financially educated readers (i.e., authorities, competitors, financial analysts, rating agencies, shareholders) that focus their attention on the risk items. In part, the high education level required could be explained if one considers that, to describe the activity of an insurance company, it is necessary to use complex words, long and complex sentences that require the reader to have a financial background to clearly understand the content of the annual report. However, at the same time, if they do not read or do not understand, stakeholders are not able to monitor, punish or reward companies based on what is disclosed. Moreover, if disclosure towards all stakeholders can be read as an indication of consumer protection (Lanam, 2008), then low levels of readability and richness, i.e., the quality of disclosure, result in reduced protection for consumers and could also be seen as a voluntary choice by companies that prefer to communicate with those stakeholders, such as financial analysts and rating agencies, who show higher levels of financial education and who are normally interested in risk information. Adopting simple and understandable language should be a duty and lead to an effort by companies towards their readers, especially for weakly financially educated ones in times of financial turbulence, giving stakeholders a tool to control and defend their interests and, at the same time, encouraging responsible behaviour and avoiding excessive risk taking by insurers, especially in the worst scenarios.

To test whether the low levels of disclosure quality could be explained as a voluntary choice to address financial information solely to a highly financially educated public, this paper employs the test for obfuscation introduced by Courtis $(1998,2004)$ and also proposed by Linsley and Lawrence (2007). It looks at the degree of variability of the READ2 scores in addition to measuring the mean, 
as high variability in levels of reading ease can affect reading behaviour as it irritates and distracts the weakly financially educated readers.

In this research, the mean value of READ2 is 31.08 and its coefficient of variation equal to 0.36 (as shown in an unreported table). This analysis is also replicated distinctly for each company, showing that approximately $38 \%$ of the companies analysed report a coefficient of variation higher than the mean, and for seven companies, it assumes values higher than 0.50 , reaching a maximum of 0.88 . Thus, for a significant portion of the sample companies, the presence of both a high reading level and high variability is documented, thus the hypothesis of a voluntary strategy to disclose towards high-level financially educated stakeholders is plausible.

The relevance of this evidence finds support in the words of the European Commission: "Given the complexity of the operations of insurers, the volume of data and the difficulty of boiling down the information available to some valid but easily understood indicators, it is far from clear that the average retail policyholder will be able to make informed choices based on comparative information regarding the financial strength of insurers. From the perspective of policyholders, it is more important that they receive clear, concise, comparable and timely information regarding the terms and conditions of insurance contracts as well as any commissions or fees paid to intermediaries" (EC, 2007, p. 83).

In this environment, "clear, concise, comparable and timely information", in one word transparent communication, seems to be a necessary but not sufficient condition for analysing the strategy towards disclosure by insurers. If the levels of readability of the insurers' annual reports remain the same in the whole time-horizon, as well as the levels of richness in the vocabulary, and if they appear as the result of a precise strategy as confirmed by the test for obfuscation, it should be at least necessary to control for the level of disclosure quantity by focusing on the heart of insurance activity, i.e., the risks undertaken by the insurance company (underwriting risk, credit risk, market risk, liquidity risk, and operational risk). The tests carried out below, looking at the quantity of risk disclosure, represent a response to this need for control.

5.1.2 The level of risk disclosure quantity: what is the quantity of risk information disclosed by European insurance companies?

In the European insurance industry, risk reporting is the main stream of disclosure as emphasised by the European Commission (EIOPA, 2013) ${ }^{16}$. Regardless of how easy to read and understandable annual reports are, the indices of risk disclosure quantity provide the amount of information insurers put in their annual reports about the risks taken and faced.

Table 6 shows the results of the new self-constructed indices of risk disclosure quantity. The risk disclosure index for insurers (RDII_O2) shows an increase over time, with average values from 16.84

\footnotetext{
16 "National competent authorities should ensure that insurance and reinsurance undertakings and groups take the appropriate steps to: a. build an effective system of governance in accordance with Solvency II Directive which provides for sound and prudent management; b. build an effective risk management system comprising strategies, processes and reporting procedures necessary to identify, measure, monitor, manage and report, on a continuous basis the risks, at an individual and at an aggregated level, to which they are or could be exposed, and their interdependencies; and c. provide qualitative information that will allow national competent authorities to evaluate the quality of the system of governance" (EIOPA, 2013, p.4, the bold text is added).
} 
in 2005 to 24.81 in 2010. These values, standardised based on formula (9), vary from 0.44 in 2005 to 0.65 in 2010 (Table 6).

Table 6

Descriptive statistics of the RDII

\begin{tabular}{|c|c|c|c|c|c|c|c|c|c|c|}
\hline \multirow{2}{*}{ Variable } & \multirow{2}{*}{ Year } & \multirow{2}{*}{ Obs. } & \multirow{2}{*}{ Mean } & \multirow{2}{*}{$\%$} & \multirow{2}{*}{ Stand.dev. } & \multirow{2}{*}{ Minimum } & \multicolumn{3}{|c|}{ Percentile } & \multirow{2}{*}{ Maximum } \\
\hline & & & & & & & $25 \%$ & $50 \%$ & $75 \%$ & \\
\hline \multicolumn{11}{|c|}{ RDII_02: Risk Disclosure Index - range 0-2 } \\
\hline & 2005 & 45 & 16.84 & 0.44 & 7.45 & 2 & 13 & 20 & 22 & 28 \\
\hline & 2006 & 47 & 19.28 & 0.51 & 6.78 & 2 & 17 & 21 & 25 & 27 \\
\hline & 2007 & 47 & 21.94 & 0.58 & 6.39 & 2 & 19 & 24 & 26 & 30 \\
\hline pre-cri & $05-2007$ & 139 & 19.39 & 0.51 & 7.14 & 2 & 17 & 21 & 25 & 30 \\
\hline & 2008 & 47 & 24.17 & 0.64 & 4.17 & 13 & 21 & 25 & 28 & 33 \\
\hline & 2009 & 46 & 24.37 & 0.64 & 5.05 & 4 & 22 & 25.5 & 28 & 35 \\
\hline & 2010 & 47 & 24.81 & 0.65 & 3.84 & 14 & 22 & 25 & 27 & 31 \\
\hline during the cri & $08-2010$ & 140 & 24.45 & 0.64 & 4.36 & 4 & 22 & 25 & 27.5 & 35 \\
\hline whole perio & 5-2010) & 279 & 21.93 & 0.58 & 6.42 & 2 & 20 & 23 & 26 & 35 \\
\hline \multicolumn{11}{|c|}{ RDII_04: Risk Disclosure Index - range 0-4 } \\
\hline & 2005 & 45 & 20.24 & 0.37 & 9.01 & 2 & 15 & 23 & 26 & 35 \\
\hline & 2006 & 47 & 22.98 & 0.43 & 8.60 & 2 & 19 & 25 & 30 & 35 \\
\hline & 2007 & 47 & 26.40 & 0.49 & 8.14 & 2 & 23 & 29 & 32 & 38 \\
\hline pre-cri & $05-2007$ & 139 & 23.25 & 0.43 & 8.89 & 2 & 18 & 25 & 30 & 38 \\
\hline & 2008 & 47 & 29.09 & 0.54 & 6.20 & 14 & 24 & 31 & 34 & 44 \\
\hline & 2009 & 46 & 29.72 & 0.55 & 7.09 & 4 & 27 & 30.5 & 34 & 45 \\
\hline & 2010 & 47 & 30.47 & 0.56 & 5.77 & 14 & 27 & 31 & 35 & 40 \\
\hline during the cri & $08-2010$ & 140 & 29.76 & 0.55 & 6.35 & 4 & 25.5 & 31 & 34 & 45 \\
\hline whole perio & $5-2010)$ & 279 & 26.52 & 0.49 & 8.37 & 2 & 22 & 28 & 32 & 45 \\
\hline
\end{tabular}

Notes: This table contains descriptive statistics of the new self-constructed risk disclosure indices for insurers (quantity of disclosure). The statistics are provided both for the score range 0-2 (RDII_02) and for the score range 0-4 (RDII_04), for each year and, then, distinctly for the pre-crisis (2005-2007) and the during the crisis (2008-2010) periods and the whole period, for all the sample companies.

The average score and its trend over time confirm that the quantity of risk disclosure in the annual reports of European insurers increases over the 2005-2010 period ${ }^{17}$. This increase is particularly strong switching from the years 2005-2007 (pre-crisis) to the years 2008-2010 (during the crisis), giving a first idea of the impact of the financial crisis on disclosure practices.

Moreover, the stronger increase between 2008 and 2010 shows that the recent financial crisis, which started in 2007 and exploded in 2008, could be an external factor affecting the disclosure choices of companies ${ }^{18}$ because disclosure is a tool to reassure all stakeholders that the insurance activity was unrelated to the financial crisis (except for AIG and Fortis ${ }^{19}$ ). Indeed, the insurance companies has contributed neither to the rise of the global financial crisis as originator or distributor of subprime mortgages nor to the diffusion of mortgage-backed financial instruments as long-term

\footnotetext{
${ }^{17}$ In an unreported table, the descriptive statistics of RDII_O2 are also provided for each of the 30 items analyzed. These statistics report interesting results, for example more than $90 \%$ of the reports have values equal to 0 just for specific items, such as the ones referred to the description of stress tests and sensitivity analyses or the quantification of other risks.

${ }^{18}$ In support of this observation, looking at the reports published during the years 2007-2010, it is clear that many pages refer to the financial crisis: i.e., the CEO, in its introductory letter to shareholders, often talks about the crisis; companies usually discuss about how they have faced or overcome the crisis. Thus, the strategy adopted by most of the companies in their disclosure is not ignoring the crisis, but talking about it, showing an awareness of the crisis, their independence from it and the strategies assumed by companies to face it.

${ }^{19}$ See (OECD, 2011).
} 
investors (Geneva Association, 2011). Further, the business model of insurers is not affected by liquidity risk as the banking institutions are: the insurers' asset-liability management is generally able to match the main cash-inflows, i.e., written premiums and income from well-diversified investment portfolio, with the main cash-outflows, i.e., pay-out claims (Starita and Malafronte, 2014).

To summarise, a large discrepancy is found: the level of quality disclosures as measured by the readability and richness indices is low and constant over time during the time horizon and seems to be the result of a deliberate strategy pursued by insurers. However, at the same time, the quantity of risk disclosure increases over the 2005-2010 time period and there is a large difference between its pre-crisis level and that during the crisis. In other words, there is no effort from the point of view of quality, but all the forces are concentrated on the description of the main issue in the insurer's management, that is the management of risks undertaken. To further enrich this first evidence, it is necessary to perform some tests on the estimated relationship between the level of disclosure quality and the risk disclosure quantity.

The idea behind this divergent behaviour is that an increase of quality is more expensive than an increase of quantity and reflects a long-term goal of communication strategy towards all the stakeholders, whereas an increase in the quantity of words on risks undertaken is a more realistic goal of a communication policy towards highly financially educated stakeholders, especially during the financial crisis.

5.1.3 Comparing the levels of disclosure quality and of risk disclosure quantity: is there divergent behaviour between quality and quantity of disclosure?

To test the estimated relationship between different levels of disclosure quality, measured by $R E A D 2$, and of risk disclosure quantity, measured by RDII_02, three checks are provided: 1) a twoway scatter plot to show the evidence of a relationship; then, 2) an analysis of the statistical significance of the correlation coefficient to test the existence of a relationship; finally, 3) the Granger test to determine if the disclosure quality causes the risk disclosure quantity or vice versa.

As such, the two-way scatter plot between READ2 and the RDII_O2 is shown in Figure 1. 


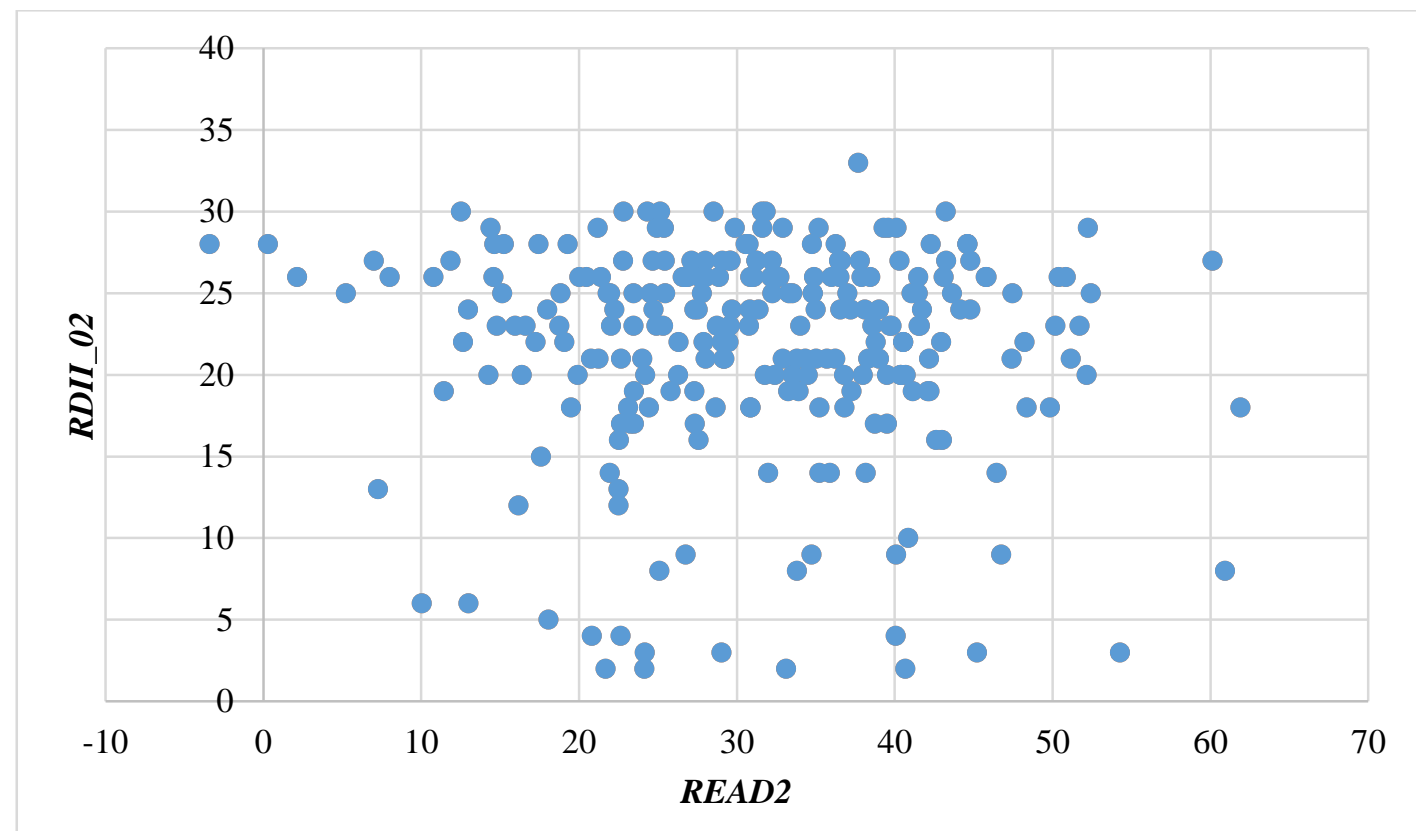

Fig.1. Scatter plot between the level of disclosure quality (READ2) and the level of risk disclosure quantity (RDII_O2).

It seems that the risk disclosure quantity measured by RDII_O2 follows a pattern that is different from that of the disclosure quality measured by READ2. As such, it seems that there is a non-linear relationship between them.

The correlation coefficient between READ2 and RDII_O2 in an unreported table is -0.04 (pvalue $=0.56$ ). Thus, it seems that no significant relationship exists between the disclosure quality and the risk disclosure quantity; the decisions assumed by companies about the quality of the entire annual reports and the amount of risk information disclosed in the management reports within the annual reports seem to follow different channels.

Moreover, when it is not obvious which variable causes which (and the variables analysed do not refer to different time periods), the Granger test can be implemented (Foresti, 2006; Casu and Girardone, 2009). Considering the regression:

$$
Y_{t}=\alpha+\phi_{1} Y_{t-1}+\beta_{1} X_{t-1}+\varepsilon_{t}
$$

it is possible to state that $\mathrm{X}$ "Granger causes" $\mathrm{Y}$ if past values of $\mathrm{X}$ can help to explain $\mathrm{Y}$ (it is not a guarantee, but it might be), if its coefficient is statistically significant.

In this paper the Granger causality test is implemented to check whether the readability level might cause the risk disclosure level, and vice versa. After confirming that the two variables are stationary (through the Dickey-Fuller test), if $\beta_{1}$ is statistically significant, it concludes that $\mathrm{X}$ Granger causes Y. 
Table 7

Results from the Granger causality test

\begin{tabular}{lllr}
\hline \multicolumn{4}{c}{ Granger Causality test } \\
\hline Dependent variable: RDII_02 & Coeff. & Dependent variable: READ2 & Coeff. \\
\hline RDII_02 (lag1) & $0.74^{* * *}$ & READ2 (lag1) & 0.07 \\
READ2 (lag1) & -0.03 & RDII_02 (lag1) & -0.08 \\
\hline
\end{tabular}

Notes: This table reports the results of the Granger causality test. The first two columns test if READ2 "Granger causes" RDII_02. The last two columns test if RDII_02 "Granger causes" READ2. *, **, *** indicate the significance level of the coefficients, respectively at $0.01,0.05$ and 0.10 .

The results in Table 7 show that READ2, which represents a measure of disclosure quality, does not Granger cause RDII_O2, which is a proxy for risk disclosure quantity, and vice versa.

To summarise, the empirical evidence provided by this study confirms the existence of divergent behaviour undertaken by insurance companies around the approach toward disclosure issues: disclosure quality is not a short term goal in the communication strategy of insurers because they prefer to concentrate efforts and financial resources on the explanation of the core of insurance activity, i.e., the management of the undertaken risks, especially during extreme financial conditions. As a result, it is interesting to investigate the determinants of risk disclosure quantity.

\subsection{Determinants of risk disclosure quantity}

This paper tries to identify the determinants of the quantity of risk disclosure by European insurers because it seems to be a less expensive goal of their communication strategy. As such, this paper focuses on factors that could explain a higher or lower risk disclosure level and designs an empirical framework to investigate the impact of a set of factors at the insurer level (size measured by gathering of premiums, operating performance expressed by ROA, and leverage measured by way of the ratio between technical provisions and the sum of total liabilities and shareholders' equity), at the country level (home country, its level of insurance development, and country-specific variables such as GDP growth rate and political stability index, alternatively), and other variables (risk measured by the ratio between the accounting value of equity and the corresponding market value, the prevalent type of insurance activity, and the year the annual report refers to) on the self-constructed index of risk disclosure quantity.

First, three specifications are run of basic "model 1" (10), which does not take into account the impact of the financial crisis (Table 8, columns 1,2, and 3). Second, the year dummies are replaced by the crisis dummy ("model 2") to estimate the effects of the financial crisis on risk disclosure quantity (Table 9, columns 1, 2 and 3).

\subsubsection{What drives the level of risk disclosure quantity in the annual reports of European insurers?}

Table 8 reports the results of the basic model (10) investigating the determinants of risk disclosure quantity by insurance companies without taking into account the impact of the financial crisis. 
Table 8

Regression results

\begin{tabular}{|c|c|c|c|}
\hline \multirow[t]{2}{*}{ Dep.Var. RDII_O2 } & \multicolumn{3}{|c|}{ Model 1} \\
\hline & coeff. & coeff. & coeff. \\
\hline SALES & $\begin{array}{c}0.969^{* *} \\
(0.40)\end{array}$ & $\begin{array}{c}1.594^{* * *} \\
(0.36)\end{array}$ & $\begin{array}{c}1.416^{* * * *} \\
(0.36)\end{array}$ \\
\hline$R O A$ & $\begin{array}{l}-11.46 \\
(11.20)\end{array}$ & $\begin{array}{c}-7.885 \\
(11.60)\end{array}$ & $\begin{array}{l}-5.140 \\
(11.54)\end{array}$ \\
\hline RESERVE & $\begin{array}{c}-5.242^{* *} \\
(2.17)\end{array}$ & $\begin{array}{c}-4.983^{* *} \\
(2.15)\end{array}$ & $\begin{array}{c}-5.294^{* *} \\
(2.14)\end{array}$ \\
\hline HOME1 & Yes & & \\
\hline HOME2-density & & $\begin{array}{c}3.019 * * * \\
(1.11)\end{array}$ & \\
\hline$G D P$ & & & $\begin{array}{l}-0.215 \\
(1.17)\end{array}$ \\
\hline STABILITY & & & $\begin{array}{c}2.476^{* * * *} \\
(0.89)\end{array}$ \\
\hline TYPE & $\begin{array}{l}-1.235 \\
(1.03)\end{array}$ & $\begin{array}{l}-0.646 \\
(1.01)\end{array}$ & $\begin{array}{l}-0.855 \\
(0.98)\end{array}$ \\
\hline RISK & $\begin{array}{l}0.674 \\
(0.57)\end{array}$ & $\begin{array}{l}0.730 \\
(0.57)\end{array}$ & $\begin{array}{l}0.571 \\
(0.58)\end{array}$ \\
\hline YEAR dummies & Yes & Yes & Yes \\
\hline Constant & $\begin{array}{c}17.47^{* * * *} \\
(4.51)\end{array}$ & $\begin{array}{c}12.41^{* * * *} \\
(4.03)\end{array}$ & $\begin{array}{c}14.90^{* * * *} \\
(3.98)\end{array}$ \\
\hline Observations & 231 & 231 & 231 \\
\hline $\mathrm{R}$-squared overall & 0.676 & 0.495 & 0.516 \\
\hline R-squared within & 0.547 & 0.546 & 0.537 \\
\hline R-squared between & 0.762 & 0.467 & 0.537 \\
\hline
\end{tabular}

Notes: This table reports the results of the regression (10) that investigates the determinants of risk disclosure practices by the sample companies. Variables are described in Table $4 . *, * *, * * *$ denote significance levels at $10 \%, 5 \%, 1 \%$. Standard errors are reported in parenthesis.

The results (Table 8, columns 1, 2 and 3) show that the SALES coefficient is always positive and statistically significant, confirming hypothesis $H_{l}$ : for example, an increase of one unit in SALES determines an increase of 0.97 (about one point score) in the level of RDII_02 (Table 8, column 1). In other words, insurers operating with a large amount of gross written premiums are more inclined to disclose about risks undertaken than those operating with less resources. In line with the previous literature (Ahmed and Courtis, 1999; Cooke, 1989, 1992, 1993; Linsley and Shrives, 2006), larger size is associated with an increase in the amount of risk information disclosed. This means that, when they become bigger, insurers as non-financial firms disclose more information on their risks; indeed, they are more in the public eye and under the influence of stakeholders; but also because their size allows to manage more money, resources and skills for investing in disclosure practices to enhance policyholder confidence. On the contrary, when the size is reduced, stakeholders have a limited influence, and, above all, the quantity of information disclosed on risk is mainly perceived as a cost because financial resources dedicated to disclosure decrease. 
The coefficient of $R O A$ is always negative and not significant, thus it fails to confirm the impact and the sign predicted by hypothesis $H_{2}$. In line with studies that document no effect of operating performance on the amount of information disclosed and in contrast with the literature that shows a positive effect (for the classification of these studies see Ahmed and Courtis, 1999), these results seem to suggest that the operating results do not have the same effect as SALES on risk disclosure quantity.

RESERVE, which is a special variable for the insurance industry, always shows a negative and significant coefficient, thus hypothesis $H_{3}$ is confirmed by the results: when the relative amount of technical provisions increases, insurers become less inclined to disclose more about the risks taken as technical provisions represent a signal of the ability to take risks by an insurance company (i.e., the strength of an insurance company) for which it is not necessary to provide more information. As such, a high level of technical provisions reassures stakeholders about the size of the risks managed by the company, justifying lower disclosure levels; at the same time, a cut in the amount of risk information disclosed may also represent a way to preserve information about risk management strategies. The opposite observations can be made for lower relative amounts of technical provisions, where an increased level of information on risks can help to reassure about the management of risks by the insurance company. As this paper previously stated, it is necessary to account for certain specific characteristics of the insurance activity, such as the relative amount of technical provisions, when identifying the levels of risk information disclosed by insurance companies.

To take into account the likely effect of the country level factors on risk disclosure quantity, the empirical design makes reference to three alternative specifications of this country effect as robustness checks: $i$ ) a country dummy for each country in the sample (see Appendix $C$ ) to measure the idiosyncratic impact of the country in which the insurance company has its head office (Table 8 , column 1); ii) a dummy that identifies the level of insurance density (see Appendix $C$ ) to test the possible effects on the risk information disclosed that depend on the level of insurance development of the country to which an insurer belongs (Table 8, column 2); iii) two macroeconomic indicators, the GDP growth rate and the political stability index, to directly link the amount of information on risks to the economic and social conditions that characterise each country (Table 8, column 3).

First, thirteen dummies are introduced to capture the home country (HOME1) of each insurer in Table 8, column 1 . Some of these dummies show a country effect on levels of risk disclosure, confirming hypothesis $H_{4}$, but due to their high number, they do not allow capturing differences in risk disclosure practices depending on the level of insurance development of the country to which an insurer belongs. With the aim of better investigating this point, the empirical design refers to the level of insurance development, i.e., the level of insurance density, as provided in the regression in Table 8, column 2. Remembering that HOME2-density takes the value of 1 if the home country is a moredeveloped country from the insurance point of view, i.e., the insurance density is higher than or equal to the sample median, it is observed that its coefficient is positive and statistically significant: it means that insurers located in more-developed countries in terms of insurance activity disclose more on the risks taken than the ones in less developed countries ${ }^{20}$. Thus, the existence of these differences in the

\footnotetext{
${ }^{20}$ These results are confirmed when the HOME2-density dummy is replaced by the HOME2-penetration dummy.
} 
levels of risk disclosure quantity is affected by the level of insurance development achieved by the home country. According to the empirical strategy, upcoming specifications will further clarify the reasons for these differences. Column 3 of Table 8 shows the impact of the GDP growth rate and of the political stability index: the first $(G D P)$ has a negative but not significant coefficient, whereas the second (STABILITY) shows a positive and significant coefficient. This means that the perception of stability at the government level as a proxy for the social conditions has a stronger impact on the amount of risk information disclosed in the insurer's annual report than do the economic conditions measured by the GDP rate. This fact will be important in the following discussion of the results because one main goal of this paper is to determine whether the financial crisis and its destabilising effects change the relationship between disclosure levels and insurer-level factors as well as countrylevel factors.

Table 8 also shows the impact of the control variables on risk disclosure quantity. The prevalent type of insurance activity (TYPE) does not significantly affect the amount of risk information disclosed; in other words, there are no differences in risk disclosure levels caused by the consideration that the insurers' activity is prevalently life or non-life. "Model 1" also controls for the relationship between the accounting value and the market value of equity (RISK), reporting a positive but not statistically significant coefficient. Moreover, six further dummies are added to control for each year (YEAR) over the period 2005-2010. The sign and significance of the year dummies statistically confirm the growing trend identified in Table 6 and suggest further investigation of the impact of the last part of the time horizon corresponding to the crisis period.

At this point, the analysis reported above is replicated to investigate the potential impact of the financial crisis on the amount of risk information disclosed to stakeholders (Table 9, columns 1, 2, and 3). Thus, differently from "model 1" presented in Table 8, the year dummies are replaced with CRISIS in "model 2", which is a dummy variable that assumes the value of 1 in the years affected by the crisis $(2008,2009,2010)$ and 0 otherwise $(2005,2006,2007)$.

The coefficient of CRISIS is positive and highly statistically significant in all the specifications of "model 2", thus a positive effect of the crisis on risk disclosure practices is documented: to underline the disconnect between the insurance sector and the origins and diffusion of the financial crisis, each insurance company invests more in the disclosure of managed risks. This can be a way to reassure stakeholders, especially those characterised by a high level of financial education, that the company is aware of the risks taken in the evolving environment and that the company is different from a banking institution as it is able to provide insurance cover against risks.

Regarding the other variables that show statistically significant coefficients, the observations just reported for "model 1" can also be replicated for this model. From this point of view, it is necessary to underline that, when taking into account the financial crisis, SALES and RESERVE drive the risk disclosure quantity as well as the country-specific variables, such as certain country dummies in column 1 of Table 9 and the level of insurance development as shown by HOME2-density in column 2 and STABILITY in column 3. 
Table 9

Regression results

\begin{tabular}{|c|c|c|c|}
\hline \multirow{2}{*}{ Dep. Var.: RDII_O2 } & \multicolumn{3}{|c|}{ Model 2} \\
\hline & coeff. & coeff. & coeff. \\
\hline \multirow[t]{2}{*}{ SALES } & $1.076^{* * *}$ & $1.719^{* * *}$ & $1.529^{* * *}$ \\
\hline & $(0.39)$ & $(0.36)$ & $(0.35)$ \\
\hline \multirow[t]{2}{*}{$R O A$} & -3.307 & 2.018 & 6.310 \\
\hline & $(11.85)$ & $(12.38)$ & (12.09) \\
\hline \multirow{2}{*}{ RESERVE } & $-4.106^{*}$ & $-3.887 *$ & $-4.310^{*}$ \\
\hline & $(2.30)$ & $(2.29)$ & $(2.25)$ \\
\hline HOME1 & Yes & & \\
\hline \multirow[t]{2}{*}{ HOME2-density } & & $3.049 * * *$ & \\
\hline & & $(1.085)$ & \\
\hline \multirow[t]{2}{*}{$G D P$} & & & -0.031 \\
\hline & & & $(0.09)$ \\
\hline \multirow[t]{2}{*}{ STABILITY } & & & $3.386^{* * *}$ \\
\hline & & & $(0.88)$ \\
\hline \multirow[t]{2}{*}{ CRISIS } & $4.178^{* * *}$ & $4.162^{* * *}$ & $4.380^{* * *}$ \\
\hline & $(0.50)$ & $(0.51)$ & $(0.61)$ \\
\hline \multirow[t]{2}{*}{ TYPE } & -1.031 & -0.378 & -0.584 \\
\hline & $(1.06)$ & $(1.05)$ & (1.01) \\
\hline \multirow[t]{2}{*}{ RISK } & 0.669 & 0.806 & 0.623 \\
\hline & $(0.62)$ & $(0.62)$ & $(0.62)$ \\
\hline \multirow[t]{2}{*}{ Constant } & $11.21^{* *}$ & 5.801 & $7.309 *$ \\
\hline & $(4.40)$ & $(4.02)$ & $(3.90)$ \\
\hline Observations & 231 & 231 & 231 \\
\hline $\mathrm{R}$-squared overall & 0.627 & 0.454 & 0.484 \\
\hline R-squared within & 0.416 & 0.416 & 0.419 \\
\hline $\mathrm{R}$-squared between & 0.759 & 0.472 & 0.543 \\
\hline
\end{tabular}

Notes: This table reports the results of a second specification of the regression (10) that investigates the determinants of risk disclosure practices by the sample companies. Variables are described in Table 4. *,**,*** denote significance levels at $10 \%, 5 \%, 1 \%$. Standard errors are reported in parenthesis.

To summarise, the differences in risk disclosure practices depend on characteristics at the insurer level, such as the amount of premiums underwritten and the strength in terms of technical provisions; at the country level, such as the home country, its level of insurance development or the social conditions perceived by people; and at the time level, such as the financial crisis.

\subsection{Discussion of results}

In summary, over the 2005-2010 time horizon insurance companies show divergent behaviour with respect to disclosure issues. On the one hand, they maintain the same level of disclosure quality in terms of readability and richness of vocabulary over time, also during the financial crisis; this means that they do not make investments to increase the level of disclosure quality. On the other hand, they strongly increase the amount of information disclosed on risks managed over time. Thus, insurance companies prefer to invest their financial resources, which are limited, in the less expensive goal of a communication strategy optimising the amount of information that is normally directed to an audience with a good financial education. Indeed, the investigation into the factors that drive the 
level of disclosure quantity shows that the amount of risk information disclosed increases with the size of the insurance company as for non-financial firms, but it decreases if the technical provisions rise. In fact, this last characteristic represents the most important way through which the company demonstrates its strength and does not require special comments for the audience of professionals with a good financial education. In addition, the quantity of information on risks is highly dependent on country variables and increases over the years of crisis. To further examine these effects, it is possible to analyse the level and trend of RDII_O2 controlling for the financial crisis with respect to the time horizon distinguishing between the pre-crisis (2005-2007) and during the crisis (2008-2010) periods (Figure 2) and the level of insurance development of the home country with respect to the two groups of more-developed and less-developed countries from the insurance point of view (Figures 3 and 4).

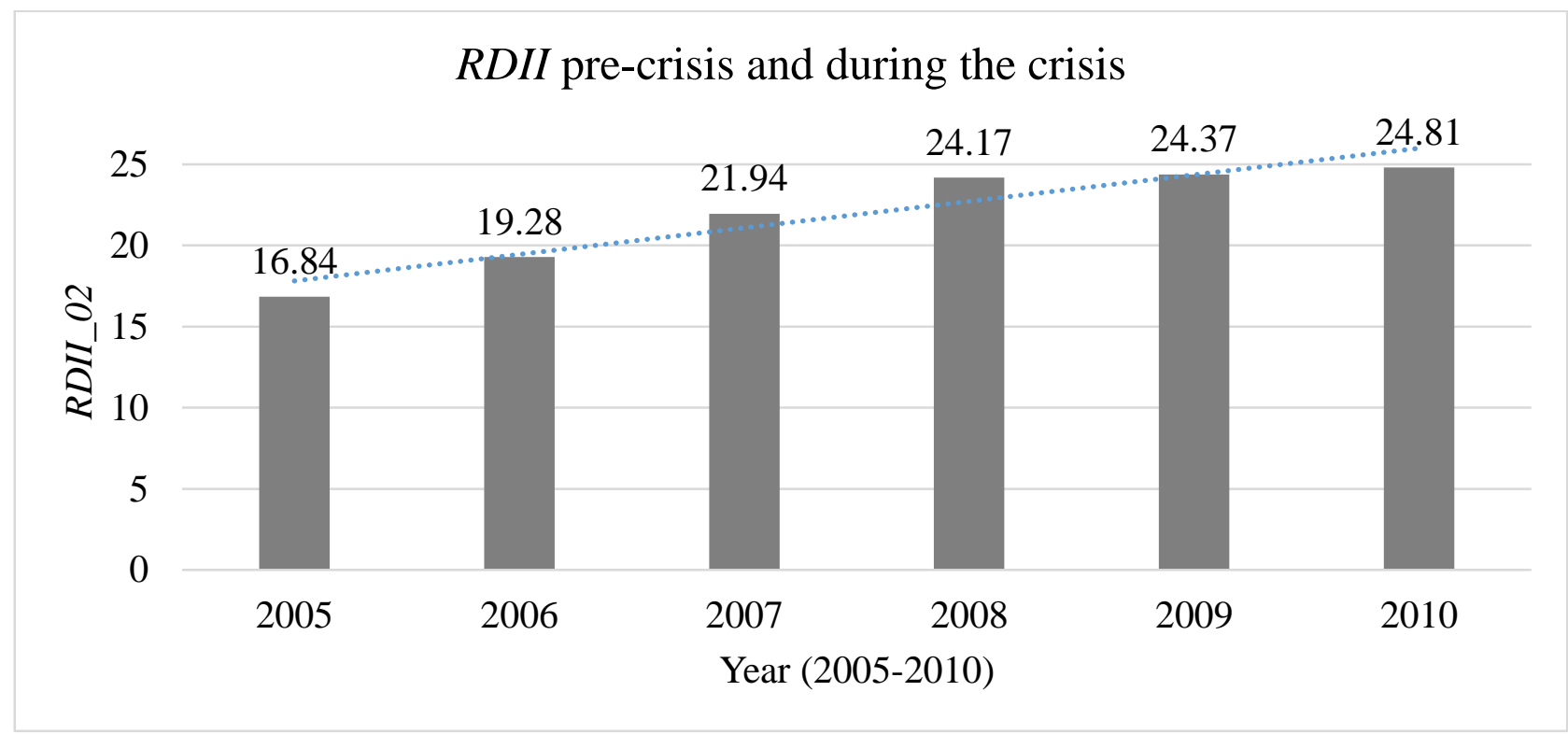

Fig.2 This figure reports the levels of risk disclosure quantity (RDII_02) for the time horizon 20052010, comparing the pre-crisis (2005-2007) with the during the crisis (2008-2010) period. 


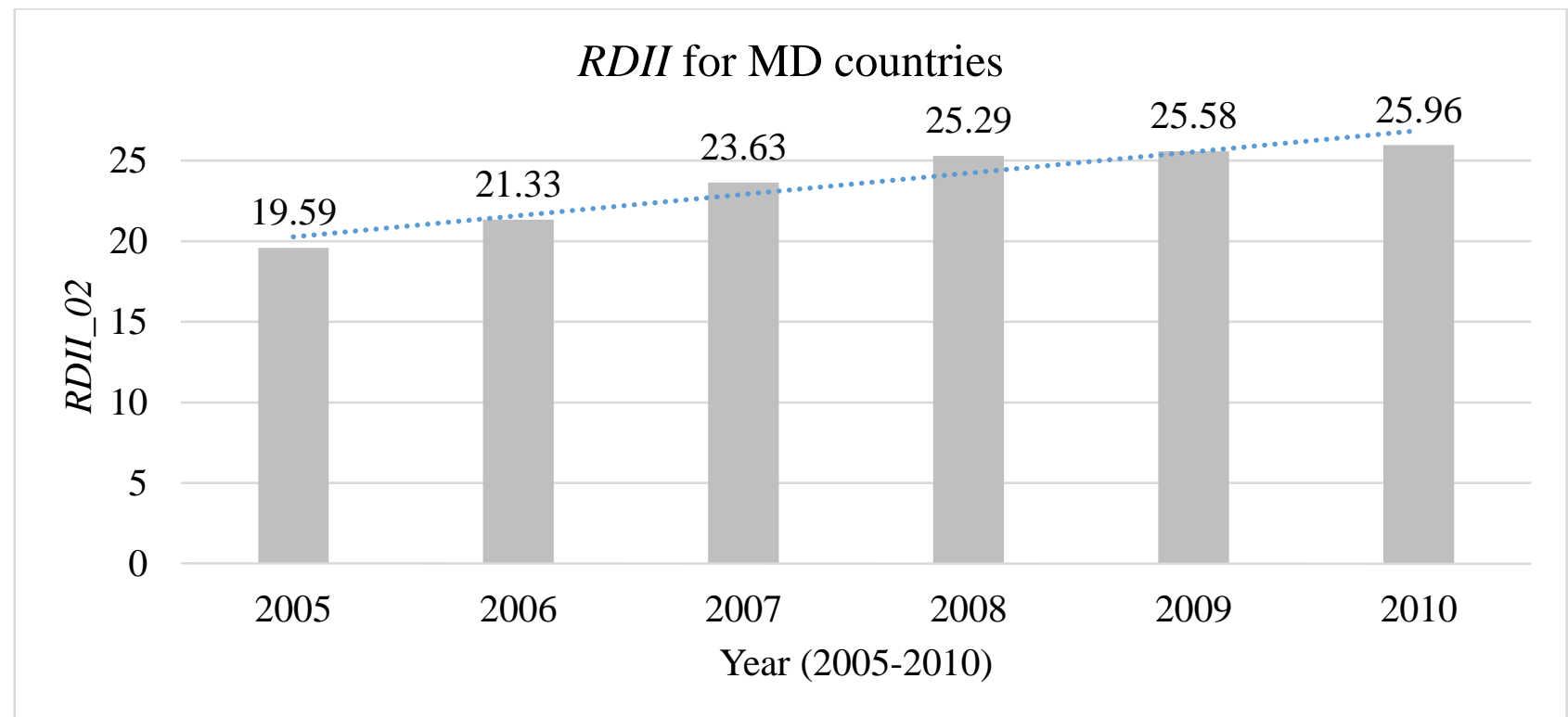

Fig.3 This figure reports the levels of risk disclosure quantity (RDII_O2) for insurers in more developed (MD) countries form the insurance point of view.

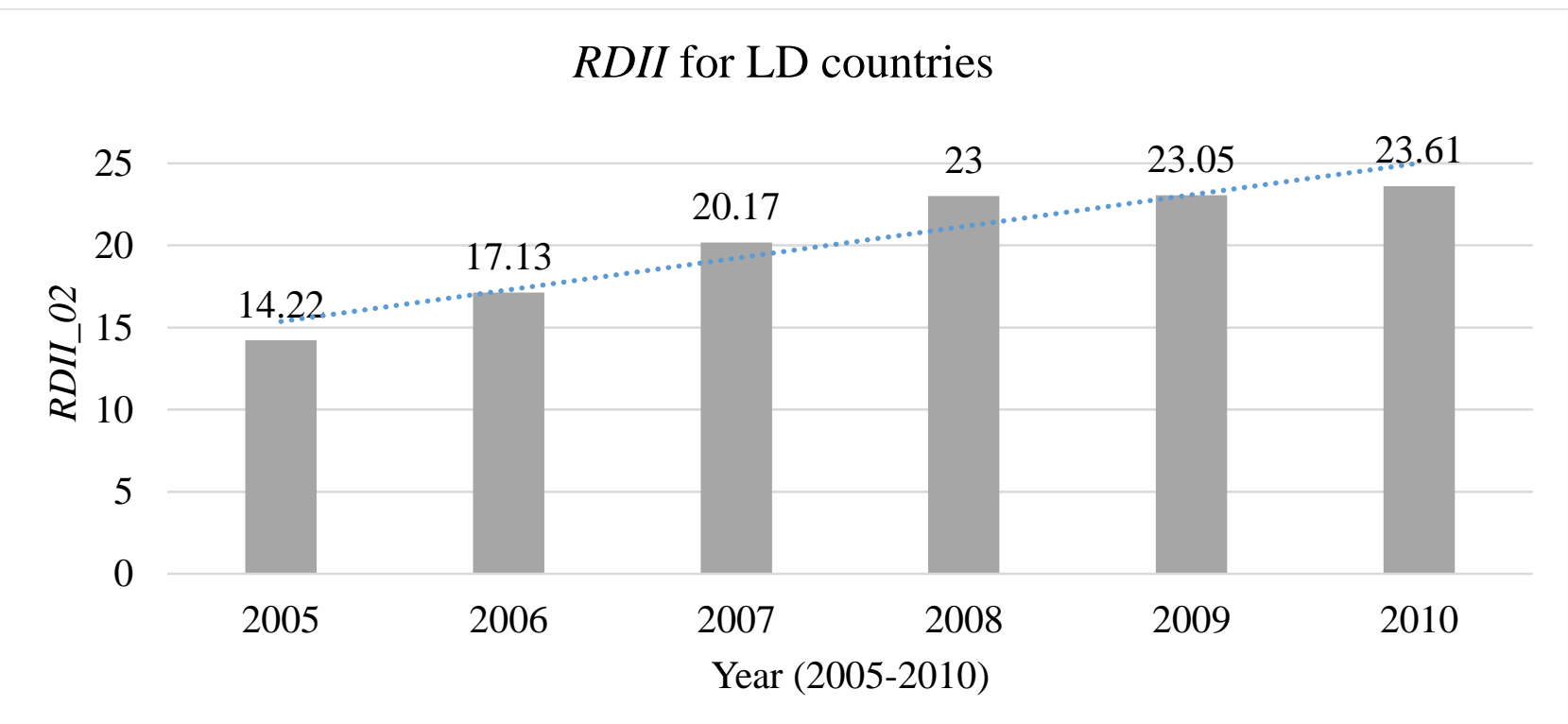

Fig.4 This figure reports the levels of risk disclosure quantity (RDII_O2) for insurers in less developed (LD) countries form the insurance point of view.

The risk disclosure index increases over time, and this enhancing trend is confirmed for all countries (Figure 2), even if it appears stronger for the companies with their legal base in lessdeveloped countries from the insurance point of view (Figure 4). The "pre crisis" - "during the crisis" comparison confirms that during the recent financial crisis all the companies, regardless of the level of insurance development in their country, strongly increased their investment in disclosure.

Thus, the evidence on the levels of disclosure shows how insurers have invested in risk disclosure quantity to highlight their independence from the global financial crisis. 
These results also shed light on the efforts that the European Union is undertaking to harmonise the supervision of insurance companies and to set a minimum for the information they disclose to the market on risk management. Thus, these results could provide interesting indications for the implementation phase and for the monitoring stage of the new regulatory framework of Solvency II, especially for the third pillar, which identifies in the supervisory reporting and the public disclosure the two main elements of the so-called "supervisor's overall need for information" (EC, 2007). In fact, the supervisory reporting consists of all the information required for solvency purposes from insurance undertakings to their supervisors, and the public disclosure from insurance undertakings to the public completes the supervisory reporting requirements, as their combination ensures for supervisors the proper identification of an insurer's risk profile (Starita and Malafronte, 2014).

\section{Conclusions}

The starting point for this research is the recognition of the potential high value assumed by disclosure in the current financial system: if relevant information is put into the public domain then participants in the marketplace can sanction unsatisfactory results, shareholders and other stakeholders (e.g., policyholders) can better manage their risk positions and the companies themselves should benefit from a reduction in their cost of finance. It also helps supervisors to be more effective in their monitoring as they are better positioned to foresee potential problems and can therefore act earlier (Linsley and Shrives, 2005). At the same time, disclosure is a complex process that succeeds only if all the actors involved - lawmakers, disclosers and disclosees - play their parts properly. Otherwise, it fails to reach its purposes (Ben-Shahar and Schneider, 2010).

This research provides new empirical evidence on the nature and determinants of disclosure practices by European insurers over the 2005-2010 time horizon, focusing on the quality of the documents and the quantity of risk information disclosed in the annual reports. After measuring the level of disclosure quality through a set of pre-defined indices and the level of risk quantity through a set of new self-constructed indices and controlling for their relationship, this research shows the existence of divergent behaviour as the quality is constant over time whereas the risk quantity increases during the entire time horizon: insurers are more inclined to invest in the quantity of information on risks than in the quality of disclosure of the entire annual report as the information on risks is addressed to more financially educated people and requires less resources than that needed for an investment in quality. At this point, the paper identifies the factors that drive the risk disclosure practices of European insurers by exploring the impacts of certain insurer-level, country-level and other variables on risk disclosure practices, also looking at the impact of the financial crisis, showing some interesting findings. Indeed, the quantity of risk disclosure depends positively on the main source of financial resources, which is the underwritten premiums, whereas risk disclosure is lower in the presence of more technical provisions, which are the most important indicator of insurance activity. The environment is also important because it impacts positively (the social conditions perceived by people and the level of insurance development) on the quantity of disclosure, and the financial crisis has a significant positive effect. To demarcate the role played in the financial crisis as providers of insurance cover against risks rather than as originators or investors in toxic assets, insurers have increased their information on risks. Hence, this research highlights how European 
insurers in the sample are focused on risk disclosure practices and invest more in disclosure during the financial crisis. To maintain market confidence, and especially the confidence of opinion leaders, the effective disclosure of relevant risk information is necessary. As such, these results have some interesting implications even accounting for the limitations of this research, which are related to: $i$ ) the quality of the sample; in fact, the analysis is focused only on the European industry, which may represent a "cluster" in the "population" of disclosure practices; $i i)$ the tool employed to derive the disclosure indices, which is the annual report. In fact, the next steps of this research are to extend the analysis on risk disclosure practices by comparing the European insurance industry with that of other Western countries (i.e., USA, Canada and Japan) and that of emerging countries (e.g., the GCC countries) and to investigate the role of other tools of disclosure, e.g., websites and social networks.

Despite these limitations, some interesting implications can be identified. First of all, if the quality of disclosure by insurers is low and constant alongside the time horizon, how is it possible to increase this level? If this goal is very expensive for the single insurer, it can become a realistic goal of regulators and authorities in the interest of European people with a weak level of financial education. Second, the quantity of information on risks provided by insurers increases over time and demonstrates an interest of insurers towards people with financial expertise. Further, there is a country effect and a social effect on risk disclosure practices that have to be accurately considered to pursue the European project on Solvency II. Third, these results seem to suggest the right level of the tradeoff between mandatory reporting and actual disclosure practices within the third pillar of Solvency II because $i$ ) the goal of increasing the quality can be pursued in the field of mandatory disclosure by providing incentives to insurers that pursue an effective policy of increasing the level of disclosure quality; $i i$ ) the goal of increasing the quantity of risk disclosure can be left to the initiatives of insurers to facilitate the adoption of the best practices in the field of risk management.

\section{Acknowledgement}

We would like to thank the anonymous reviewers for their valuable comments and suggestions to improve the quality of the paper. We are also grateful to all the participants of the Surrey Fordham Conference on "Banking, Finance, Money and Institutions: The Post Crisis Era" held at the University of Surrey in November 2013. 


\section{Appendix A - Qualitative disclosure}

This appendix contains the description of the indices introduced for measuring qualitative disclosure in the annual reports of the sample companies. It refers to seven indices: the first five indices (Readability Indices) measure the readability of the documents and, as a result, indicate the ease of reading or the grade level required to read and understand the text; the last two indices (Richness Indices) indicate the richness of the vocabulary used.

\begin{tabular}{ll}
\hline Variable & Description \\
\hline Readability Indices & \\
1) Gunning's Fog Index & grade level necessary to understand a text \\
2) Flesch Index & ease of reading of a text \\
3) Kincaid Index & grade level necessary to understand a text \\
4) Coleman-Liau Index & grade level necessary to understand a text \\
5) Automated Readability Index & grade level necessary to understand a text \\
\hline Richness Indices & \\
6) Type/Token Ratio (TTR) & variety of the text vocabulary \\
7) Hapax Index & number of words with frequency=1 \\
\hline
\end{tabular}

The Gunning's Fog Index (READ1) was elaborated in 1952 by Robert Gunning, an American textbook publisher. It expresses the minimum number of school years that a person needs to attend in order to read easily the text analyzed and understand it on a first reading. The mathematical formula is (1):

FOGIndex $=0.4($ ASL + PHW $)=0.4[($ words $/$ sentences $)+100($ complexwords $/$ words $)]$

where ASL is the Average Sentence Length, calculated as the number of words divided by the number of sentences; PHW is the Percentage of Hard Words, the ratio between complex words and the total number of words in the passage. Complex words are long words, conventionally composed of three or more syllables. It awards shorter sentences than longer sentences written in complicated language. The result is a Grade Level according to the U.S. grade levels: the ideal score is 7 or 8; anything above 12 is too hard for most people to read (otherwise, the average person reads at level 9, easy reading range is 6-10 and anything above 15 is getting difficult).

The Flesch Index (READ2) was formulated by the American scholar Rudolph Flesch, the first who stated that the readability of a text can be measured. The mathematical formula of the Flesch Index is (2):

$$
\begin{gathered}
\text { Flesch }=206.835-1.015 A S L-84.6 \text { ASW }=206.835-1.015 \text { (tot. } \text { words } / \text { tot. sentences })- \\
\text { 84.6(tot. syllables } / \text { tot.words })
\end{gathered}
$$

where ASL is the Average Sentence Length, calculated as the number of words divided by the number of sentences; $A S W$ is the Average Number of Syllables per word, calculated as the number of syllables divided by the number of words. The results have a range between 0 and 100, where 100 indicates the highest level of readability and the easier to read (documents easily understood by an average 11-year-old student), 0 the worst or more difficult to read (documents best understood by university graduates).

The Flesch-Kincaid Index (READ3) is an elaboration of the Flesch Index, in the sense that it translates the 0100 score into a grade level. The mathematical formula of the Flesch-Kincaid Index is (3):

$$
\begin{gathered}
\text { Kincaid }=0.39 A S L+11.8 A S W-15.59=0.39(\text { tot. } w o r d s / \text { tot. sentences })+11.8(\text { tot. syllables } / \\
\text { tot. } \text { words })-15.59 \text { (3) }
\end{gathered}
$$


The score corresponds to a grade level, the number of years of education required to understand the text.

The Coleman-Liau Index (READ4) indicates the grade level necessary to understand a text; differently from the indices presented above, it considers the number of characters included in the text. The mathematical formula is (4):

$$
\begin{gathered}
\text { CLGrade }=5.89 A C W-0.3(\text { sentences } / 100 \text { words })-15.8=5.89(\text { characters } / \text { words })- \\
0.3(\text { sentences } / 100 \text { words })-15.8
\end{gathered}
$$

where $A C W$ is the Average Characters per Word, calculated as the number of characters divided by the number of words.

The Automated Readability Index (READ5) represents the US grade level needed to comprehend the text. The mathematical formula is (5):

$$
A R I=4.71 A V L+0.5 A V W-21.43=4.71(\text { character } s / \text { words })+0.5(\text { words } / \text { sentences })-21.43
$$

where $A V L$ is the average number of letters per word and $A V W$ is the average number of words in sentences.

The Type/Token Ratio (READ6) is a measure of the richness of the vocabulary. The mathematical formula is (6):

$$
\operatorname{TTR}=V / N \quad(6)
$$

where $V$ represents the text vocabulary (number of types or lemma), $N$ is the length of the text in terms of number of words (number of tokens). Generally, the number of tokens is greater than the number of types. Higher values assumed by this index indicate more richness in the vocabulary.

The Hapax Index (READ7) is a measure of the richness of the vocabulary, its lexical variety and lexical sophistication. The mathematical formula is (7):

$$
\text { Hapax }=V_{\text {Hapax }} / N
$$

where $V_{\text {Hapax }}$ indicates the number of words that occurs once in the text, $N$ represents the number of tokens. The results indicate the percentage of words with frequency equal to one. 


\section{Appendix B - Quantitative disclosure}

This appendix contains the list of the 30 items that compose the risk disclosure index for insurers (RDII) and the potential scores assignable to each of them, that could have the range 0-2 (RDII_02) or 0-4 (RDII_04). The items of the total risk disclosure index concern seven areas: i) Risk management (4 items); ii) Underwriting risk (4 items); iii) Market risk (4 items); iv) Credit risk (4 items); v) Operational risk (4 items); vi) Liquidity risk (4 items); vii) Other risks (6 items). Regarding the RDII_02, some items is assigned a score equal to "0" or " 1 ": " 0 " when there is no disclosure and " 1 " when the information is provided. For the remaining items the score is between " 0 " and "2": "0" when there is no disclosure, " 1 " when the information is provided in a basic way, " 2 " when the information is provided in an extensive way. Regarding the RDII_04, some items is assigned a score equal to " 0 " or " 1 ": " 0 " when there is no disclosure and " 1 " when the information is provided. For the remaining items the score is between " 0 " and " 4 ": " 0 " when there is no disclosure, " 1 " when the information is provided in a basic way, " 2 ", " 3 " or " 4 " when the information is provided in an extensive way, depending on the depth of the information provided. The choice about the range (0-1, 0-2 and 0-4) depends on the type and the depth that each item could have.

\begin{tabular}{|c|c|c|c|}
\hline $\mathrm{N}$ & Items & RDII_O2 & RDII_04 \\
\hline \multicolumn{4}{|c|}{ RISK MANAGEMENT } \\
\hline 1 & List and definition of risks & $0-1$ & $0-1$ \\
\hline 2 & Description of capital adequacy approach & $0-1$ & $0-1$ \\
\hline 3 & Description of capital requirements & $0-2$ & $0-4$ \\
\hline 4 & Description of risk management policies & $0-2$ & $0-4$ \\
\hline \multicolumn{4}{|c|}{ UNDERWRITING RISK } \\
\hline 5 & Definition of the risk & $0-1$ & $0-1$ \\
\hline 6 & Description of risk mitigation activities & $0-1$ & $0-1$ \\
\hline 7 & Quantification of risks & $0-1$ & $0-1$ \\
\hline 8 & Description of stress tests and sensitivity analysis & $0-2$ & $0-4$ \\
\hline \multicolumn{4}{|c|}{ MARKET RISK } \\
\hline 9 & Definition of the risk & $0-1$ & $0-1$ \\
\hline 10 & Description of risk mitigation activities & $0-1$ & $0-1$ \\
\hline 11 & Quantification of risks & $0-1$ & $0-1$ \\
\hline 12 & Description of stress tests and sensitivity analysis & $0-2$ & $0-4$ \\
\hline \multicolumn{4}{|c|}{ CREDIT RISK } \\
\hline 13 & Definition of the risk & $0-1$ & $0-1$ \\
\hline 14 & Description of risk mitigation activities & $0-1$ & $0-1$ \\
\hline 15 & Quantification of risks & $0-1$ & $0-1$ \\
\hline 16 & Description of stress tests and sensitivity analysis & $0-2$ & $0-4$ \\
\hline \multicolumn{4}{|c|}{ OPERATIONAL RISK } \\
\hline 17 & Definition of the risk & $0-1$ & $0-1$ \\
\hline 18 & Description of risk mitigation activities & $0-1$ & $0-1$ \\
\hline 19 & Quantification of risks & $0-1$ & $0-1$ \\
\hline 20 & Description of stress tests and sensitivity analysis & $0-2$ & $0-4$ \\
\hline \multicolumn{4}{|c|}{ LIQUIDITY RISK } \\
\hline 21 & Definition of the risk & $0-1$ & $0-1$ \\
\hline 22 & Description of risk mitigation activities & $0-1$ & $0-1$ \\
\hline 23 & Quantification of risks & $0-1$ & $0-1$ \\
\hline 24 & Description of stress tests and sensitivity analysis & $0-2$ & $0-4$ \\
\hline \multicolumn{4}{|c|}{ OTHER RISKS } \\
\hline 25 & Identification of other risks & $0-1$ & $0-1$ \\
\hline 26 & Quantification of other risks & $0-1$ & $0-1$ \\
\hline 27 & Rating & $0-1$ & $0-1$ \\
\hline 28 & Competitive environment/Market share & $0-1$ & $0-1$ \\
\hline 29 & Historical results & $0-2$ & $0-4$ \\
\hline 30 & Forward-looking data & $0-1$ & $0-1$ \\
\hline
\end{tabular}




\section{Appendix C - Composition of the sample by country}

This table reports the composition of the final sample by country. For each country it is reported its levels of insurance density and insurance penetration, the distribution of the observations in terms of the number of companies and the prevalent type of insurance activity (life and non-life).

\begin{tabular}{lcccccccc}
\hline \multirow{2}{*}{\begin{tabular}{c}
\multirow{2}{*}{$\begin{array}{c}\text { Insurance } \\
\text { density }\end{array}$} \\
Insurance
\end{tabular}} & $\begin{array}{c}\text { Insuro } \\
\text { penetration }^{22}\end{array}$ & \multicolumn{2}{c}{$\begin{array}{c}\text { Number of } \\
\text { companies }\end{array}$} & \multicolumn{2}{c}{$\begin{array}{c}\text { Subsector: } \\
\text { Life }\end{array}$} & \multicolumn{2}{c}{$\begin{array}{c}\text { Subsector: } \\
\text { Non-life }\end{array}$} \\
\cline { 4 - 8 } & & & Freq. & Perc. & Freq. & Perc. & Freq. & Perc. \\
\hline Austria & $1,999.16$ & 0.06 & 2 & 4.26 & 2 & 9.09 & 0 & 0 \\
Denmark & $3,779.04$ & 0.12 & 2 & 4.26 & 0 & 0 & 2 & 8 \\
Finland & $3,481.78$ & 0.12 & 1 & 2.13 & 0 & 0 & 1 & 4 \\
France & $3,205.39$ & 0.12 & 4 & 8.51 & 2 & 9.09 & 2 & 8 \\
Germany & $2.186,30$ & 0.07 & 3 & 6.38 & 1 & 4.55 & 2 & 8 \\
Great Britain & $3,335.74$ & 0.13 & 12 & 25.53 & 6 & 27.27 & 6 & 24 \\
Italy & $2,083.53$ & 0.08 & 5 & 10.63 & 3 & 13.64 & 2 & 8 \\
Netherlands & $4,698.52$ & 0.14 & 4 & 8.51 & 4 & 18.18 & 0 & 0 \\
Norway & $2,837.38$ & 0.07 & 2 & 4.26 & 1 & 4.55 & 1 & 4 \\
Poland & 355.15 & 0.02 & 1 & 2.13 & 0 & 0 & 1 & 4 \\
Slovene & $1,022.96$ & 0.05 & 1 & 2.13 & 0 & 0 & 1 & 4 \\
Spain & $1,224.34$ & 0.05 & 2 & 4.26 & 0 & 0 & 2 & 8 \\
Switzerland & $3,652.20$ & 0.10 & 5 & 10.63 & 3 & 13.64 & 2 & 8 \\
Turkey & 97.28 & 0.01 & 3 & 6.38 & 0 & 0 & 3 & 12 \\
\hline Total & - & - & 47 & 100.00 & 22 & 100.00 & 25 & 100.00 \\
\hline
\end{tabular}

\footnotetext{
${ }^{21}$ The sample median is $3,270.56$.

22 The sample median is 0.10 .
} 


\section{References}

Abraham, S., Cox, P. (2007). Analysing the determinants of narrative risk information in UK FTSE 100 annual reports. The British Accounting Review, vol.39, n.3, pp. 227-248, doi:10.1016/j.bar.2007.06.002.

Abraham, S., Solomon, A., Stevenson, J. (2007). A Ranking of Risk Disclosure in UK Annual Reports. Available at SSRN Electronic Paper Collection.

Adams, M., Hossain, M. (1998). Managerial discretion and voluntary disclosure: Empirical evidence from the New Zealand life insurance industry. Journal of Accounting and Public Policy, vol.17, n.3, pp. 245281, doi:10.1016/S0278-4254(98)10003-0.

Ahmed, K., Courtis, J.K. (1999). Associations between corporate characteristics and disclosure levels in annual reports: a meta-analysis. British Accounting Review, vol.31, n.1, pp.35-61, doi:10.1006/bare.1998.0082.

Barakat, A., Hussainey, K. (2013). Bank governance, regulation, supervision, and risk reporting: Evidence from operational risk disclosure in European banks. International Review of Financial Analysis, vol.30, pp.254-273, doi:10.1016/j.irfa.2013.07.002.

Barako, D.G., Hancock, P., Izan, H.Y. (2006). Factors Influencing Voluntary Corporate Disclosure by Kenyan Companies. Corporate Governance: An International Review, vol.14, n.2, pp.107-125, doi: 10.1111/j.14678683.2006.00491.x.

Barth, M. E., Landsman, W. R. (2010). How did Financial Reporting Contribute to the Financial Crisis? European Accounting Review, vol.19, n.3, pp.399-423, doi: 10.1080/09638180.2010.498619.

Baumann, U., Nier, E. (2004). Disclosure, Volatility, and Transparency: An Empirical Investigation into the Value of Bank Disclosure. FRBNY Economic Policy Review, vol. 10, n. 2, pp. 31-45.

Belth, J.M. (1968). Price disclosure in life insurance. Business Horizons, vol.11, n.3, pp.29-36.

Belth, J.M. (1976). Life Insurance: A Case Study in Deceptive Sales Practices and the Need for Disclosure. Business and Society Review, vol.75/76(16), pp.34-41.

Ben-Shahar, O., Schneider, C.E. (2010). The Failure of Mandated Disclosure. Available at The Chicago Working Paper Series and SSRN Electronic Paper Collection.

Berelson, B. (1952). Content Analysis in Communication Research. New York: Free Press.

Beretta, S. (2007). No news bad news. Perchè e come comunicare informazioni economico finanziarie su base volontaria. SDA AeC. Quaderni professionalità amm. Egea.

Beretta, S., Bozzolan, S. (2004). A framework for the analysis of firm risk communication. The International Journal of Accounting, vol.39, n.3, pp. 265-288, doi:10.1016/j.intacc.2004.06.006.

Beretta, S., Bozzolan, S. (2008). Quality versus Quantiy: The Case of Forward-Looking Disclosure. Journal of Accounting, Auditing \& Finance, vol. 23, n. 3, pp. 333-376, doi:10.1177/0148558X0802300304.

Beuselinck, C., Deloof, M., Manigart, S., (2008). Private Equity Investments and Disclosure Policy. European Accounting Review, Vol. 17, n. 4, pp. 607-639, doi: 10.1080/09638180802327057.

Botosan, C.A. (1997). Disclosure Level and the Cost of Equity Capital. The Accounting Review, vol. 72, n. 3 , pp. 323-349, Stable URL: http://www.jstor.org/stable/248475.

Camfferman, K., Cooke, T.E. (2002). An Analysis of Disclosure in the Annual Reports of U.K. and Dutch Companies. Journal of International Accounting Research, vol.1, n.1 pp. 3-30, doi: http://dx.doi.org/10.2308/jiar.2002.1.1.3.

Casu, B., Girardone, C. (2009). Does Competition Lead to Efficiency? The Case of EU Commercial Banks. Working Paper Series 01/09, Cass Business School.

CEA (2011). European Insurance in Figures. CEA Statistics n. 44.

Chavent, M., Ding, Y., Fu, L., Stolowy, H., Wang, H., (2006). Disclosure and Determinants Studies: An Extension Using the Divisive Clustering Method (DIV). European Accounting Review, vol.15, n.2, pp. 181218, doi: 10.1080/09638180500253092.

Cooke, T.E. (1989). Disclosure in the Corporate Annual Reports of Swedish Companies. Accounting and Business Research, vol.19, n.74, pp. 113-124, doi: 10.1080/00014788.1989.9728841.

Cooke, T.E. (1992). The Impact of Size, Stock Market Listing and Industry Type on Disclosure in the Annual Reports of Japanese Listed Corporations. Accounting and Business Research, vol.22, n.87, pp. 229-237, doi: 10.1080/00014788.1992.9729440.

Cooke T.E. (1993). Disclosure in Japanese corporate annual reports. Journal of Business Finance \& Accounting, vol.20, n.4, pp.521-535, doi: 10.1111/j.1468-5957.1993.tb00272.x. 
Courtis, J. K. (1998). Annual report readability variability: Tests of the obfuscation hypothesis. Accounting, Auditing and Accountability Journal, vol.11(4), pp.459-471.

Courtis, J. K. (2004). Corporate report obfuscation: Artifact or phenomenon? The British Accounting Review, vol. 36(3), pp.291-312.

Cude, B.J. (2006). Insurance Disclosures: An Effective Mechanism to Increase Consumers' Insurance Market Power? Journal of Insurance Regulation, vol.24, n.2, pp.57-80.

Deumes, R. (2008). Corporate risk reporting. Journal of Business Communication, vol. 45, n. 2, pp. 120-157.

EC (2007). Impact Assessment Report. SEC (2007) 871, available at www.ec.europa.eu/internal_market/insurance/solvency/future.htm.

EIOPA (2013). Guidelines on the System of Governance. EIOPA-CP-13/08, available at www.eiopa.europa.eu.

Elshandidy, T., Fraser, I., Hussainey, K. (2013). Aggregated, voluntary, and mandatory risk disclosure incentives: Evidence from UKFTSE all-share companies. International Review of Financial Analysis, vol.30, pp.320-333, doi:10.1016/j.irfa.2013.07.010.

Feyen, E., Lester, R., Rocha, R. (2011). What Drives the Development of the Insurance Sector? An Empirical Analysis Based on a Panel of Developed and Developing Countries. Policy Research Working Paper 5572, available at www.worldbank.org.

Foresti, P. (2006). Testing for Granger causality between stock prices and economic growth. Munich Personal RePEc Archive (MPRA), Paper n. 2962.

Francis, J., Nanda, D., Olsson, A.P. (2007). Voluntary Disclosure, Earnings Quality, and Cost of Capital. Journal of Accounting Research, vol.46, n.1, pp.53-99, doi: 10.1111/j.1475-679X.2008.00267.x.

Geneva Association (2010). The Global Financial Crisis and the Insurance Industry. Frequently Asked Questions, available at www.genevaassociation.org.

Hail, L. (2011). Discussion of Consequences and Institutional Determinants of Unregulated Corporate Financial Statements: Evidence from Embedded Value Reporting. Journal of Accounting Research, vol.49, n.2, pp.573-594, doi: 10.1111/j.1475-679X.2011.00404.x.

Helbok, G., Wagner, C. (2005). Determinants of Operational Risk Reporting in the Banking Industry. Available at SSRN Electronic Paper Collection.

Hirtle, B. (2007). Public Disclosure, Risk, and Performance at Bank Holding Companies. FRBNY Staff Reports, n. 293.

Ho, S.S.M., Wong, K.S. (2001). A study of the relationship between corporate governance structures and the extent of voluntary disclosure. Journal of International Accounting, Auditing and Taxation, vol.10, n.2, pp. 139-156, doi:10.1016/S1061-9518(01)00041-6.

Höring, D., Gründl, H. (2011). Investigating Risk Disclosure Practices in the European Insurance Industry. The Geneva Papers on Risk and Insurance, vol.36, pp.380-413, doi:10.1057/gpp.2011.13.

Kirsch, L. (2003). Do Product Disclosures Inform and Safeguard Insurance Policyholders? Journal of Insurance Regulation, vol.20, n.3, pp. 271-295.

Klumpes, P., Kumar, A., Dubey, R. (2014). Investigating risk reporting practices in the global insurance industry. British Actuarial Journal, vol.19, n.3, pp.692-727, doi: http://dx.doi.org/10.1017/S1357321714000087.

Krippendorff, K. (2004). Content Analysis. An Introduction to Its Methodology. Second Edition. Thousand Oaks: Sage Publications.

Lajili, K., Zeghal, D. (2005). A Content Analysis of Risk Management Disclosures in Canadian Annual Reports. Canadian Journal of Administrative Sciences, vol.22, n.2, pp.125-142, doi: 10.1111/j.19364490.2005.tb00714.x.

Lanam, L. (2007). Consumer Disclosure as Consumer Protection. Journal of Insurance Regulation, vol. 26, n. 2.

Lanam, L. (2008). Consumer disclosure as consumer protection. Journal of Insurance Regulation, 26(2).

Lang, M., Lundholm, R. (1993). Cross-sectional determinants of analyst ratings of corporate disclosures. Journal of Accounting Research, vol.31, n.2, pp.246-271, doi: 10.2307/2491273.

Linsley, P.M., Lawrence, M.J. (2007). Risk reporting by the largest UK companies: readability and lack of obfuscation. Accounting, Auditing \& Accountability Journal, vol.20, n.4, pp.620-627, http://dx.doi.org/10.1108/09513570710762601.

Linsley, P.M., Shrives, P.J. (2005). Transparency and the disclosure of risk information in the banking sector. Journal of Financial Regulation and Compliance, vol.13, n.3, pp.205-214, http://dx.doi.org/10.1108/13581980510622063. 
Linsley, P.M., Shrives, P.J. (2006). Risk reporting: A study of risk disclosures in the annual reports of UK companies. The British Accounting Review, vol.38, n.4, pp. 387-404, doi:10.1016/j.bar.2006.05.002.

Marston, C.L. (1991). The use of disclosure indices in accounting research: A review article. The British Accounting Review, vol.23, n.3, pp.195-210, doi:10.1016/0890-8389(91)90080-L.

OECD (2011). The Impact of the Financial Crisis on the Insurance Sector and Policy Responses. Available at www.oecd.org.

Oliveira, J., Rodrigues, L.L., Craig, R. (2011). Risk-related disclosure practices in the annual reports of Portuguese credit institutions: An exploratory study. Journal of Banking Regulation, vol.12, n.2, pp.100118, doi:10.1057/jbr.2010.20.

Perignon, C., Smith, D.R. (2010). The level and quality of Value-at-Risk disclosure by commercial banks. Journal of Banking \& Finance, vol.34, n.2, pp.362-377, doi:10.1016/j.jbankfin.2009.08.009.

Starita, M. G., Malafronte, I. (2014). Capital Requirements, Disclosure, and Supervision in the European Insurance Industry. New Challenges towards Solvency II. Basingstoke: Palgrave MacMillan.

Sundmacher, M. (2006). Consistency of risk reporting in financial services firms. Available on SSRN Electronic Paper Collection, http://dx.doi.org/10.2139/ssrn.963245.

van Oorschot, L. (2010). Risk Reporting: An Analysis of the German Banking Industry. Erasmus University Rotterdam, pp. 147-165. 